\title{
ACPD
}

\section{An explicit study of aerosol mass conversion and its parameterization in warm rain formation of cumulus clouds}

\section{J. Sun ${ }^{1,2,3,4}$, J. Fen ${ }^{3}$, and R. K. Ungar ${ }^{4}$}

${ }^{1}$ Key Laboratory of Cloud-Precipitation Physics and Severe Storms (LACS),Institute of Atmospheric Physics, Chinese Academy of Sciences, China

${ }^{2}$ Collaborative Innovation Center on Forecast and Evaluation of Meteorological Disasters, Nanjing University of Information Science and Technology, China

${ }^{3}$ Meteorological Service of Canada, Environment Canada, Canada

${ }^{4}$ Verification and Incident Monitoring Radiation Protection Bureau, Health Canada, Canada

Received: 22 July 2013 - Accepted: 16 September 2013 - Published: 2 October 2013

Correspondence to: J. Sun (jimings@ @mail.iap.ac.cn) and J. Feng (jian.feng @ec.gc.ca)

Published by Copernicus Publications on behalf of the European Geosciences Union.

Aerosol conversion parameterizations in warm rain formation of cumulus clouds

J. Sun et al.

\section{Title Page}

Abstract

Conclusions

Tables

14

Back
Introduction

References

Figures

$\rightarrow 1$

Close

Full Screen / Esc

Printer-friendly Version

Interactive Discussion 


\section{Abstract}

The life time of atmospheric aerosols is highly affected by in-cloud scavenging processes. Aerosol mass conversion from aerosols embedded in cloud droplets into aerosols embedded in raindrops is a pivotal pathway for wet removal of aerosols in 5 clouds. The aerosol mass conversion rate in the bulk microphysics parameterizations is always assumed to be linearly related to the precipitation production rate, which includes the cloud water autoconversion rate and the cloud water accretion rate. The ratio of the aerosol mass concentration conversion rate to the cloud aerosol mass concentration has typically been considered to be the same as the ratio of the precipitation production rate to the cloud droplet mass concentration. However, the mass of an aerosol embedded in a cloud droplet is not linearly proportional to the mass of the cloud droplet. A simple linear relationship cannot be drawn between the precipitation production rate and the aerosol mass concentration conversion rate. In this paper, we studied the evolution of aerosol mass concentration conversion rates in a warm rain formation process with a 1.5-dimensional non-hydrostatic convective cloud and aerosol interaction model in the bin microphysics. We found that the ratio of the aerosol mass conversion rate to the cloud aerosol mass concentration can be statistically expressed by the ratio of the precipitation production rate to the cloud droplet mass concentration with an exponential function. We further gave some regression equations to determine aerosol conversions in the warm rain formation under different threshold radii of raindrops and different aerosol size distributions.

\section{Introduction}

Aerosol scavenging is an important issue related to aerosol indirect and direct effects on climate and aerosol effects on precipitation. In-cloud aerosol scavenging includes in-cloud nucleation scavenging and in-cloud impaction scavenging. In-cloud nucleation scavenging is a dominant process of aerosol scavenging in the atmosphere (Schu-
Aerosol conversion parameterizations in warm rain formation of cumulus clouds

J. Sun et al.

Title Page

Abstract Introduction

Conclusions

References

Tables

Figures

14

-1

4

Back

Close

Full Screen / Esc

Printer-friendly Version

Interactive Discussion 
mann, 1991), which refers to the processes of aerosol activation as cloud condensation nuclei (CCN) and ice nuclei (IN). Aerosol mass conversion from aerosols inside cloud droplets into aerosols inside raindrops is a key pathway for wet removal of aerosols in cumulus clouds. It is therefore crucial to be able to represent the physical conversion 5 processes of aerosol mass from aerosols inside cloud droplets into aerosols inside raindrops through the stochastic coalescence process in atmospheric models.

Estimates of the aerosol mass concentration conversion rates in the warm rain formation are essential for numerical modeling studies in climate change, precipitation prediction and air pollution evaluation. To determine aerosol mass transfer between 10 cloud hydrometeors in the cumulus cloud simulations with the bin microphysics has always been treated as an indispensable procedure after every collision between them (Flossmann et al., 1985; Chen and Lamb, 1994; Kogan et al., 1995; Ackerman et al., 1995; Feingold et al., 1996; Xue et al., 2010; Ovchinnikov and Easter, 2010; Lebo and Seinfeld, 2011). However, such an estimation in the simulations with the bulk microphysics is only considered when precipitation-sized hydrometeors occur. The latter approach in terms of the aerosol mass concentration conversion rates involves the calculations of the nucleation scavenging efficiency and the precipitation production rate, both of which have descended from the work of Junge and Gustafson (1957). The efficiency of nucleation scavenging is used to determine the aerosol mass concentration in hydrometeors (Liu and Wang, 1996). The precipitation production rate refers to the cloud liquid water content conversion rate from cloud droplets to drizzle or raindrops through the autoconversion and accretion processes. An explicit determination of the mass conversion rates for both aerosols and cloud droplets may be possible in some models with the bin microphysics in which the aerosol mass and the water 25 mass in each of hydrometeors are both explicitly followed. The computation limitation impedes the application of such a treatment of microphysics into two or three dimensional models. Therefore, mass conversion rates for aerosols and hydrometeors are both still necessarily handled implicitly within the bulk microphysics (Gong et al., 2007; Ivanova and Leighton, 2008; Croft et al., 2010; Kazil et al., 2011). The autoconversion

\section{ACPD}

13, 25481-25536, 2013

Aerosol conversion parameterizations in warm rain formation of cumulus clouds

J. Sun et al.

Title Page
Abstract

Conclusions

Tables

14

4

Back
Introduction

References

Figures

-1

$>$

Close
Full Screen / Esc

Printer-friendly Version

Interactive Discussion 
rate and the accretion rate have been applied to express a conversion rate of cloud droplets to drizzle by the cloud-to-rain autoconversion (Seifert and Beheng, 2001) and a conversion rate of cloud droplets to raindrops by the rain accretion (Cohard and Pinty, 2000; Seifert and Beheng, 2001), respectively.

5 The autoconversion rate has been parameterized in different ways (Berry, 1968; Kessler, 1969; Manton and Cotton, 1977; Baker, 1993; Beheng, 1994; Rotstayn, 1997; Khairoutdinov and Kogan, 2000; Cohard and Pinty, 2000; Seifert and Beheng, 2001; Liu and Daum, 2004). Berry (1968) proposed an autoconversion scheme as a function of the number concentration of cloud droplets, the mixing ratio of cloud water and 10 the diameter dispersion of cloud droplets. Kessler (1969) proposed one expression which assumes autoconversion rates linearly dependent on the cloud liquid water content. Manton and Cotton (1977) suggested that autoconversion rates are related to the cloud droplet concentration, the drop mean volume radius, the mean droplet collision efficiency and the threshold radius. In recent decades, autoconversion rates have been parameterized in terms of the cloud droplet number concentrations (Baker, 1993; Rotstayn, 1997; Khairoutdinov and Kogan, 2000) and the spectral dispersion (Beheng, 1994; Cohard and Pinty, 2000; Seifert and Beheng, 2001; Liu and Daum, 2004).

Different autoconversion parameterizations must result in different autoconversion rates of cloud droplets. The autoconversion rates determined by different schemes can vary up to three orders of magnitude (Cotton and Anthes, 1989; Wood and Blossey, 2005). However, all autoconversion parameterizations try to describe a part of the coalescence process of cloud droplets. This process can be derived from the Stochastic Collection Equation (SCE) (Pruppacher and Klett, 1997):

$R_{\text {Auto }}=\frac{1}{2} \int_{m_{0}}^{m_{\mathrm{a}}} \int_{m_{0}+m_{\mathrm{a}}-m}^{m_{\mathrm{a}}} g(m) K\left(m, m^{\prime}\right)\left(m+m^{\prime}\right) g\left(m^{\prime}\right) \mathrm{d} m^{\prime} \mathrm{d} m$

${ }_{25} \quad m_{\mathrm{a}}=\frac{4}{3} \pi r_{\mathrm{a}}^{3} \cdot \rho_{\text {water }}$

ACPD

13, 25481-25536, 2013

Aerosol conversion parameterizations in warm rain formation of cumulus clouds

J. Sun et al.

Title Page

Abstract

Introduction

Conclusions

References

Tables

Figures

14

$>1$

4

Back

Close

Full Screen / Esc

Printer-friendly Version

Interactive Discussion 
where $K\left(m, m^{\prime}\right)$ is the collection kernel and $g(m)$ is the cloud droplet distribution function. $m_{\mathrm{a}}$ is the separation mass between cloud droplets and drizzle, $r_{\mathrm{a}}$ is the separation radius.

The above equation reflects the dependence of autoconversion rates on the separa5 tion radius. Values of the separation radius have been assumed to be different radii in various parameterization schemes. The smallest threshold radius has been defined at $25 \mu \mathrm{m}$ (Khairoutdinov and Kogan, 2000). The largest threshold radius has been assumed to be $50 \mu \mathrm{m}$ (Berry and Reinhardt, 1974; Beheng and Doms, 1986). However, the value of the separation radius is often set to $40 \mu \mathrm{m}$ in many studies (Beheng 10 and Doms, 1986; Beheng, 1994; Cohard and Pinty, 2000; Seifert and Beheng, 2001; Franklin, 2008; Kogan, 2013).

The accretion rate has been parameterized as a function of the liquid water content of rain including drizzle, the liquid water content of cloud droplets, the concentration of raindrops, the collision efficiency between cloud droplets and raindrops. Kessler (1969) 15 proposed that accretion rates are proportional to the mixing ratio of cloud droplets and the mixing ratio of raindrops. Wisner and Myers (1972) and Orville and Kopp (1977) proposed that accretion rates are related to the liquid water content of cloud droplets, the concentration of raindrops and the collision efficiency between cloud droplets and raindrops.

20 Different accretion schemes also result in different accretion rates in bulk microphysics. The accretion rate can also be expressed in the SCE (Pruppacher and Klett, 1997):

$R_{\text {Accr }}=\int_{m=m_{0}}^{m_{\mathrm{a}}} \int_{m^{\prime}=m_{\mathrm{a}}}^{\infty} g(m) K\left(m, m^{\prime}\right) m g\left(m^{\prime}\right) \mathrm{d} m^{\prime} \mathrm{d} m$

The parameterizations of autoconversion and accretion processes will indirectly affect the modeling of wet removal of aerosols because this removal process is often scaled by the precipitation production rates in aerosol-cloud interaction models with 25485

\section{ACPD}

13, 25481-25536, 2013

Aerosol conversion parameterizations in warm rain formation of cumulus clouds

J. Sun et al.

Title Page

Abstract

Introduction

Conclusions

References

Tables

Figures

14

$>1$

4

Back

Close

Full Screen / Esc

Printer-friendly Version

Interactive Discussion
D

teractive Discussion

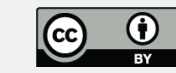


bulk microphysics. Application of different parameterizations of the precipitation production rates into in-cloud aerosol nucleation scavenging models must result in different aerosol mass conversion rates. Furthermore, there is also a question with whether a simple proportional relationship can be drawn between the precipitation production 5 rates and the rates of aerosol mass conversion from cloud droplets into raindrops, since there may not be a direct relationship between cloud water mass and aerosol mass amongst the cloud droplets. Even though the parameterization schemes of the precipitation production rates themselves highly impact the estimation accuracy of wet removal of aerosols, it may be another factor involved in this estimation accuracy that 10 we always took the intensity of the aerosol mass concentration conversion rate (the ratio of the aerosol mass concentration conversion rate to the aerosol mass concentration inside cloud droplets) as the intensity of the conversion rate of the cloud droplet mass concentration (the ratio of the precipitation production rate to the cloud droplet mass concentration). It should be noted that the aerosol mass inside a cloud droplet is not linearly proportional to the mass of the cloud droplet. The aerosol mass fraction of a cloud droplet directly depends on the initial aerosol size distribution and the factors impacting the cloud droplet growth, such as aerosol concentrations.

To understand aerosol mass transfer, and then to improve the aerosol conversion algorithm in the warm rain formation, it is necessary to simulate the evolution of aerosol particle spectra regulated by cloud droplet spectra in a convection with bin microphysics. This paper has three objectives. First, we have done some simulations to elucidate the temporal and spatial evolution of the autoconversion rates and the accretion rates of aerosol particles and that of the corresponding rates for cloud droplets in the warm rain formation. Second, we compare different approaches to represent the aerosol mass conversion in response to the cloud droplet conversion and to figure out an optimum algorithm under conditions of different aerosol concentrations and of different threshold radii of raindrops. Finally, we further evaluate the impacts of the aerosol size distributions on the aerosol mass conversions.
ACPD

13, 25481-25536, 2013

Aerosol conversion parameterizations in warm rain formation of cumulus clouds

J. Sun et al.

Title Page
Abstract

Conclusions

Tables

14

4

Back

Full Screen / Esc
Printer-friendly Version

Interactive Discussion 


\section{Explicit algorithms for the cloud droplet conversions and the aerosol conversions in the warm rain formation}

ACPD

The ratio of the cloud water autoconversion rate to the cloud droplet mass concentration $R_{\mathrm{c} \text {-auto }}$ (the intensity of the cloud water autoconversion rate) can be described as 5 follows:

$R_{\text {c-auto }}=\frac{\frac{1}{2} \int_{m_{0}}^{m_{\mathrm{a}}} \int_{m_{0}+m_{\mathrm{a}}-m}^{m_{\mathrm{a}}} g(m) K\left(m, m^{\prime}\right)\left(m+m^{\prime}\right) g\left(m^{\prime}\right) \mathrm{d} m^{\prime} \mathrm{d} m}{\int_{m_{0}}^{m_{\mathrm{a}}} m g(m) \mathrm{d} m}$

The ratio of the cloud water accretion rate to the cloud droplet mass concentration $R_{\mathrm{c}-\mathrm{accre}}$ (the intensity of the cloud water accretion rate) can be described as follows:

$R_{\text {c-accre }}=\frac{\int_{m=m_{0}}^{m_{\mathrm{a}}} \int_{m^{\prime}=m_{\mathrm{a}}}^{\infty} g(m) K\left(m, m^{\prime}\right) m g\left(m^{\prime}\right) \mathrm{d} m^{\prime} \mathrm{d} m}{\int_{m=m_{0}}^{m_{\mathrm{a}}} m g(m) \mathrm{d} m}$

10 The ratio of the total conversion rate of the cloud droplet mass concentration to the cloud droplet mass concentration $R_{\mathrm{c}-\mathrm{conv}}$ (the intensity of the precipitation production rate) is given as follows:

$R_{\mathrm{c}-\mathrm{conv}}=R_{\mathrm{c} \text {-auto }}+R_{\mathrm{c} \text {-accre }}$

Aerosols can be transferred from aerosols inside cloud droplets into aerosols inside 15 drizzle or raindrops when collisions between water drops occur. For the autoconversion of cloud droplets to drizzle, the ratio of the aerosol mass concentration autoconversion rate to the aerosol mass concentration inside cloud droplets $R_{\text {a-auto }}$ (the intensity of the aerosol autoconversion rate) can be expressed as follows:

Aerosol conversion parameterizations in warm rain formation of cumulus clouds

J. Sun et al.

Title Page

Abstract

Conclusions

Tables

14

4

Back
Introduction

References

Figures

$\Delta \mathbf{I}$

D

Close

Full Screen / Esc

Printer-friendly Version

Interactive Discussion 
$R_{\text {a-auto }}=\frac{\frac{1}{2} \int_{m_{0}}^{m_{\mathrm{a}}} \int_{m_{0}+m_{\mathrm{a}}-m}^{m_{\mathrm{a}}} \int_{m_{\mathrm{p} 0}}^{m_{\mathrm{p}}} \int_{m_{\mathrm{p} 0}}^{m_{\mathrm{p} \infty}} f\left(m, m_{\mathrm{p}}\right) K\left(m, m^{\prime}\right)\left(m_{\mathrm{p}}+m_{\mathrm{p}}^{\prime}\right) f\left(m^{\prime}, m_{\mathrm{p}}^{\prime}\right) \mathrm{d} m_{\mathrm{p}}^{\prime} \mathrm{d} m_{\mathrm{p}} \mathrm{d} m^{\prime} \mathrm{d} m}{\int_{m_{0}}^{m_{\mathrm{a}}} \int_{m_{\mathrm{p} 0}}^{m_{\mathrm{pa}}} m_{\mathrm{p}} f\left(m, m_{\mathrm{p}}\right) \mathrm{d} m_{\mathrm{p}} \mathrm{d} m}$

where $m_{\mathrm{po}}$ is the minimum mass of aerosols inside cloud droplets, and $m_{\mathrm{po}}$ is the maximum mass of aerosols inside cloud droplets. $f\left(m, m_{\mathrm{p}}\right)$ is the number distribution function of cloud droplets with water mass $m$, which contains aerosol mass $m_{\mathrm{p}}$.

5 As for the accretion of cloud droplets to drizzle and raindrops, the ratio of aerosol mass concentration accretion rate to the aerosol mass concentration in cloud droplets $R_{\mathrm{a}-\mathrm{accre}}$ (the intensity of the aerosol accretion rate) can be expressed as follows:

$R_{\mathrm{a}-\mathrm{accre}}=\frac{\int_{m_{0}}^{m_{\mathrm{a}}} \int_{m_{\mathrm{a}}}^{\infty} \int_{m_{\mathrm{p} 0}}^{m_{\mathrm{p} \infty}} \int_{m_{\mathrm{p} 0}}^{m_{\mathrm{p} \infty}} f\left(m, m_{\mathrm{p}}\right) K\left(m, m^{\prime}\right) m_{\mathrm{p}} f\left(m^{\prime}, m_{\mathrm{p}}^{\prime}\right) \mathrm{d} m_{\mathrm{p}}^{\prime} \mathrm{d} m_{\mathrm{p}} \mathrm{d} m^{\prime} \mathrm{d} m}{\int_{m_{0}}^{m_{\mathrm{a}}} \int_{m_{\mathrm{p} 0}}^{m_{\mathrm{pa}}} m_{\mathrm{p}} f\left(m, m_{\mathrm{p}}\right) \mathrm{d} m_{\mathrm{p}} \mathrm{d} m}$

In order to study aerosol conversions in the warm rain formation, we also defined the 10 aerosol conversion ratio $R_{\text {a-conv }}$ (the intensity of the aerosol conversion rate) including both the aerosol accretion ratio and the aerosol autoconversion ratio as follows:

$R_{\mathrm{a} \text {-conv }}=R_{\mathrm{a} \text {-auto }}+R_{\mathrm{a} \text {-accre }}$

\section{A cumulus cloud model and gravitational-hydrodynamic collisions}

We used a 1.5-D cumulus cloud spectral model (Sun et al., 2012a) to study aerosol 15 itly determine aerosol mass transfer after collisions between all kinds of hydrometeors in the simulations of cumulus clouds. We assumed that ammonium sulfate is the only $\mathrm{CCN}$ in our simulations. The aerosol redistribution algorithm after a collision follows the method of Bott (2000). The algrithm of the stochastic collision and coalescence follows

ACPD

13, 25481-25536, 2013

Aerosol conversion parameterizations in warm rain formation of cumulus clouds

J. Sun et al.

Title Page

Abstract

Introduction

Conclusions

References

Tables

Figures

14

$\Delta \mathbf{I}$

4

Back

Close

Printer-friendly Version

Interactive Discussion 
the approach of Monier et al. (2006). The number density distribution of aerosol particles and water droplets (including aerosol particles) are described by a number density distribution function $f\left(\ln m_{\text {water }}, \ln m_{\text {aerosol }}, z\right)$ with respect to the natural logarithm of mass. $f\left(\ln m_{\text {water }}, \ln m_{\text {aerosol }}, z\right) \mathrm{d} \ln m$ is the number of hydrometeors per unit volume with 5 masses in the interval between the $\ln m$ and $\ln m+d \ln m$. In a three dimensional discrete mass grid coordinate, $f(j, i, k)$ is used to represent $f\left(\ln m_{\text {water }}, \ln m_{\text {aerosol }}, z\right) \mathrm{d} \ln m$, $j$ and $i$ are the mass grid with $m_{\text {water/aerosol }}(j+1 / i+1)=2^{1 / 4} m_{\text {water/aerosol }}(j / i)$, yielding a doubling of the particle mass after four grid cells. Aerosol particles have 180 bins with radius from $8.0 \times 10^{-3}$ to $2.42 \times 10^{2} \mu \mathrm{m}$, and water drops have 240 bins with radius from $8.0 \times 10^{-3} \mu \mathrm{m}$ to $7.74 \times 10^{3} \mu \mathrm{m}$.

In this model the collision processes includes both the collisions between aerosols and water droplets and the collisions of themselves. The collisions occur mainly through Brownian motion and hydrodynamic capture (Koziol and Leighton, 2007). As for a gravitational-hydrodynamic collision, which is a dominate collision way between water 15 droplets, the hydrodynamic interaction between them impacts their collision efficiencies because their relative motion modifies the drag forces of particles. The accurate way to determine their collision efficiencies can be performed by a direct simulation of the motion for two spheres in the flow field generated by both of them. However, it is not easy to obtain a solution by this way. According to some studies (Beard, 1974; Koziol and 20 Leighton, 2007), this issue can be largely simplified for the collisions between small particles and large particles. Beard (1974) simplified the two-sphere problem by assuming that the smaller particle moves in the flow field generated by the larger particle; the weak flow field generated by the smaller particle can be neglected. This method is reasonable under the conditions in which the collecting droplet diameters range from 25

$80 \mu \mathrm{m}$ to $1200 \mu \mathrm{m}$, the size of collected particles is larger than $1 \mu \mathrm{m}$, and their ratio of radii is less than 0.1 . This simplified approach can be used to simulate the large and giant aerosol scavenging process by rain droplets (Pflaum and Pruppacher, 1979; Hall, 1980). But this treatment is not reasonable for simulating warm-rain initiation, in which the beginning sizes of coalescence nuclei are normally smaller than $70 \mu \mathrm{m}$. Beard and

\section{ACPD}

13, 25481-25536, 2013

Aerosol conversion parameterizations in warm rain formation of cumulus clouds

J. Sun et al.

Title Page
Abstract

Conclusions

Tables

14

Back
Introduction

References

Figures

$>1$

Close
Full Screen / Esc

Printer-friendly Version 
Ochs (1993) suggested that the most appropriate treatment for the flow around interacting spheres should include both viscous and inertial terms in the Navier-Stokes equation for the warm-rain initiation problem, such as the approach of Klett and Davis (1973). Hall (1980) summarized the collision efficiency derived by various authors as 5 a function of drop sizes. These data on the collision efficiency were used in our model.

\section{A simulation of the warm rain formation}

The initial size distribution and concentration of aerosols will dominate the evolution of cloud droplet spectra and then affect the warm rain formation. However, a large variety of aerosol size distributions and concentrations have been observed in different places

(Whitby, 1978; Fitzgerald, 1991; O'Dowd et al., 1997; Vakkari et al., 2013). To study the aerosol mass conversion, numerical sensitivity experiments are needed under different aerosol size distributions and concentrations (Fig. 1). Therefore, we first simulate aerosol mass transfer under the condition of the same aerosol size distribution which is a combination distribution of two aeorosl size distributions given by Fitzgerald (1991) 15 and O'Dowd et al. (1997) and of the different aerosol concentrations of the test cases employed by Sun et al. (2012a) (Table 1). We further examine the effects of different aerosol size distributions on aerosol conversions with single lognormal aerosol distributions (Nenes and Seinfeld, 2003) and triple lognormal aerosol distributions (Whitby, 1978) (Table 1). Single-modal cases SM1, SM2, and SM5 have the same standard deviation and mean dry diameter, but their total number concentration varies from marine aerosol concentrations to continental aerosol concentrations. The case SM3 with a small standard deviation represents a much narrower size distribution compared with other single-modal cases. The mean diameter moves from $0.02 \mu \mathrm{m}$ of SM1 to $0.2 \mu \mathrm{m}$ of $\mathrm{SM} 4$, representing an aerosol concentration increase in large sizes, as the total number concentration remains unchanged. Trimodal cases cases TM1-M, TM1-C, TM1-B, and TM1-U are representative of marine, clean continental, average background, and urban aerosol concentrations and distributions, repectively. We chose an idealized case

\section{ACPD}

13, 25481-25536, 2013

Aerosol conversion parameterizations in warm rain formation of cumulus clouds

J. Sun et al.

Title Page

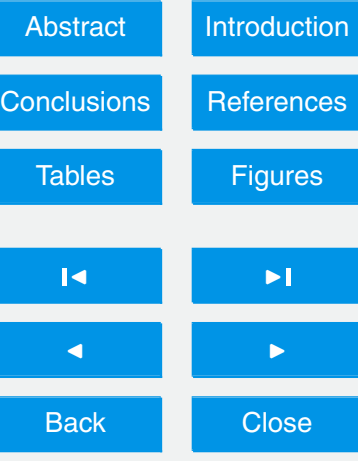

Full Screen / Esc

Printer-friendly Version

Interactive Discussion 
of cumulus clouds (Yau, 1980; Sun et al., 2012a) to simulate the warm rain formation. Since we only focus on aerosol conversions in the warm rain formation, the ice phase has not been considered in all our simulations. Table 2 shows numerical test cases with different concentrations of ammonium sulfate particles, different separation radii of 5 raindrops and different aerosol size distributions.

Figure 2a shows the temporal and spatial evolution of cloud liquid water content and vertical velocity for the case $E_{1}$. The maximum values of cloud liquid water content and vertical velocity reach $3.5 \mathrm{~g} \mathrm{~m}^{-3}$ and $7.6 \mathrm{~m} \mathrm{~s}^{-1}$, respectively. The warm rain occurs at the simulation of $50 \mathrm{~min}$, which results from the stochastic collision and coalescence processes between water drops. Figure $2 \mathrm{~b}$ presents the evolution of mass concentration of ammonium sulfate. As for warm-based precipitating cumulus clouds, the in-cloud aerosol scavenging is mainly involved in the warm rain formation. The evolution of the ammonium sulfate mass concentrations shows that in-cloud aerosols dissolved or attached on raindrops fall from the cloud to the ground in the simulation. The evolution of 15 the mass concentration of ammonium sulfate quite matches the trajectory of raindrops. The high centre of the mass concentration of ammonium sulfate is also the high centre of rain water content (Fig. 2b). Flossmann et al. (1985) found that the main aerosol mass concentration is always associated with the main cloud liquid water content. Our results further show that the main aerosol mass concentration may be coincident with the main rain water content in the warm rain formation.

The coincidence of the high aerosol mass concentration with the high rain water content in the early precipitation stage is partly due to the aerosol size distribution of the case $E_{1}$. Even though the number concentration of large aerosol particles is normally small compared with the total number concentration of aerosols, their mass concentration occupies a relatively high proportion of the total mass concentration. The aerosols with large sizes will be activated firstly and then grow into large cloud droplets. As a result, the large nucleated cloud droplets with relatively high mass concentrations of ammonium sulfate may readily act as rain embryos to initiate the collision and coalescence processes. Therefore, the unit of rain water content should contain more aerosol

Aerosol conversion parameterizations in warm rain formation of cumulus clouds

J. Sun et al.

Title Page

Abstract

Conclusions

Tables

14

Back

Full Screen / Esc

Printer-friendly Version

\section{1}


mass than that of cloud liquid water content in the early developing stage of cumulus clouds. On the other hand, the raindrop sedimentation itself can redistribute the spatial aerosol mass concentration. The aerosol mass concentration inside water drops in the trajectories of raindrops will be enhanced due to an additional aerosol mass concentra5 tion inside raindrops. The phenomena of the falling raindrops containing high aerosol mass concentrations and the small aerosol mass concentrations over the upper part of the cloud (Fig. 2b) indicate that the most of large aerosols in the cloud have been scavenged.

\section{Ammonium sulfate conversions in the warm rain formation}

10 The conversion rates of water mass and of aerosol mass can be determined by a comparison of the mass redistributions for both water drops and aerosols inside them after one time step of the stochastic collision and coalescence processes. The conversion rates determined by this approach can reflect aerosol mass conversions and water mass conversions from cloud droplets into raindrops in the whole possible coalescence processes between cloud droplets and raindrops and even among themselves. We termed this method as the complete coalescence approach (CCA). However, we also need to know aerosol autoconversion rates and aerosol accretion rates for any microphysics schemes with the bulk microphysics parameterizations. Therefore, we need further to resolve the Eqs. (1) and (3). It should be emphasized that Eqs. (1) and (3) only describe the growth rates of some prescribed water drops with radii greater than the threshold radius at the expense of cloud droplets with radii less than this radius for a specific cloud spectrum. Therefore, Eqs. (1) and (3) cannot represent the description of the whole stochastic coalescence processes for one cloud droplet spectrum. The solutions to Eqs. (4), (5), (7) and (8) cannot account for the effects of the evolution of cloud droplet spectra on the aerosol conversions completely. The latter approach may approximately represent aerosol mass conversions and water mass conversions in the warm rain formation. The solutions to Eqs. (4), (5), (7) and (8) are called approximate

\section{ACPD}

13, 25481-25536, 2013

Aerosol conversion parameterizations in warm rain formation of cumulus clouds

J. Sun et al.

Title Page
Abstract

Conclusions

Tables

14

4

Back
Introduction

References

Figures

$>1$

Close
Full Screen / Esc

Printer-friendly Version

Interactive Discussion 
conversions as a result of the partial coalescence approach (PCA). The difference of these two approaches will be compared in our simulations.

Figure $3 \mathrm{a}$ shows the ratios of $R_{\mathrm{a} \text {-conv }}$ to $R_{\mathrm{c} \text {-conv }}$ by the complete coalescence approach. We can find that these ratios vary between 0.48 and 5.4 during the warm rain 5 formation process. Note that these ratios are larger than 1.0 at the beginning of precipitation production and less than 1.0 at the early precipitation stage. Figure $3 b$ shows the spatial and temporal evolution of $R_{\mathrm{a}-\mathrm{conv}}$ and $R_{\mathrm{c} \text {-conv }}$. The variation of $R_{\mathrm{a}-\mathrm{conv}}$ matches that of $R_{\mathrm{c} \text {-conv }}$ quite well when both of them are greater than $10^{-3} \mathrm{~s}^{-1}$. The difference between $R_{\mathrm{a} \text {-conv }}$ and $R_{\mathrm{c} \text {-conv }}$ becomes prominent during the early developing stage of 10 the cloud while $R_{\mathrm{a}-\mathrm{conv}}$ and $R_{\mathrm{c} \text {-conv }}$ are both less than $10^{-3} \mathrm{~s}^{-1}$ before the simulation of $35 \mathrm{~min}$. The intensity of the precipitation production rate $R_{\mathrm{c} \text {-conv }}$ and the intensity of the aerosol conversion rate $R_{\mathrm{a} \text {-conv }}$ are both highly related to the prescribed threshold diameter of raindrops. The high concentrations of raindrops with the threshold diameter of $80 \mu \mathrm{m}$ and of $100 \mu \mathrm{m}$ appear at the upper part of the cloud (Fig. 3c). Whereas, the high concentrations of raindrops with the threshold diameter of $50 \mu \mathrm{m}$ occurs in the most parts of the cloud. As a result, the distributions of the ratios of $R_{\mathrm{a} \text {-conv }}$ to $R_{\mathrm{c} \text {-conv }}$ in the cloud must be different under the different scenarios of the threshold diameter for raindrops. These differences will be discussed the Sect. 7 .

Figure 4a shows three kinds of conversion ratios determined by the partial coales20 cence approach. The ratios of $R_{\mathrm{a} \text {-conv }}$ to $R_{\mathrm{c} \text {-conv }}$ with this scheme are generally larger than those calculated by the complete coalescence approach. The minimum ratio of $R_{\mathrm{a}-\mathrm{conv}}$ to $R_{\mathrm{c} \text {-conv }}$ during the early precipitation stage becomes larger than 1.0 . Comparing Figs. $3 \mathrm{~b}$ and $4 \mathrm{~b}$, we can find that the larger intensity of the ammonium sulfate conversion rate with this scheme result in slightly overestimated ammonium sulfate conversion ratios in the cloud. This overestimates are mainly due to the lack of consideration for the coalescence processes within every time step between cloud droplets in which their combined radii after coalescence are less than the threshold raindrop radii, which leads to the number concentrations of large cloud droplets with low mass concentrations of ammonium sulfate become low. As a result, the concentration of the

Aerosol conversion parameterizations in warm rain formation of cumulus clouds

J. Sun et al.

Title Page

Abstract

Conclusions

Tables

14

4

Back
Introduction

References

Figures

$\Delta \mathbf{I}$

Close

Full Screen / Esc

Printer-friendly Version

Interactive Discussion 
large cloud droplets involving in autoconversion processes with the scheme of PCA possibly excludes those containing relatively low mass concentrations of ammonium sulfate.

It is worth noting that the autoconversion ratios are much larger than 1.0 and the 5 accretion ratios are around 1.0 in the cloud (Fig. $4 \mathrm{a}$ ). These results are very different from what we have assumed that both of those ratios are equal to 1.0. We also found that the evolution of the autoconversion of cloud water is not always coincident with that of the accretion of cloud water, which means that the accretion rate of cloud droplets is not always proportional to the autoconversion rate of cloud droplets. Cloud droplet au10 toconversion mainly occurs in the upper part of the cloud (Fig. 4c) due to cloud droplet spectrum broadening (Sun et al., 2012b). The maximum value of the autoconversion rates of cloud droplets reaches $0.0006 \mathrm{~g} \mathrm{~m}^{-3} \mathrm{~s}^{-1}$. However, large cloud water accretion rates also appear in the low part of the cloud when precipitation occurs (Fig. 4c). The maximum value of the accretion rates of cloud water reaches $0.0065 \mathrm{~g} \mathrm{~m}^{-3} \mathrm{~s}^{-1}$. 15 The maximum value of the precipitation production rates reaches $0.0084 \mathrm{~g} \mathrm{~m}^{-3} \mathrm{~s}^{-1}$. The temporal and spatial evolutions of such conversion rates of cloud water determine those of ammonium sulfate. Corresponding, there is a band of large ammonium sulfate autoconversion rates in the upper part of the cloud (Fig. 4d). The maximum of the autoconversion rates of ammonium sulfate mass concentration reaches $5.0 \times 10^{-7} \mathrm{~g} \mathrm{~m}^{-3} \mathrm{~s}^{-1}$. On the other hand, large ammonium sulfate accretion rates appear to increase the aerosol conversion in the middle and the low part of the cloud (Fig. 4d). The maximum of the accretion rate of ammonium sulfate mass concentration is $1.0 \times 10^{-6} \mathrm{~g} \mathrm{~m}^{-3} \mathrm{~s}^{-1}$. The accretion rate of ammonium sulfate is also not always proportional to the autoconversion rate of ammonium sulfate.

To study the evolution of the autoconversion and the accretion, we further plot the number distributions of water drops and of ammonium sulfate particles at the two different developing stages of the cloud (Fig. 5). Comparing Fig. 5a and b, we can find that the size distributions of ammonium sulfate particles in the different altitudes have been changed little after cloud droplet nucleation took place during the early develop-

\section{ACPD}

13, 25481-25536, 2013

Aerosol conversion parameterizations in warm rain formation of cumulus clouds

J. Sun et al.

Title Page
Abstract

Conclusions

Tables

14

4

Back
Introduction

References

Figures

-I

Close
Full Screen / Esc

Printer-friendly Version

Interactive Discussion 
ing stage of the warm rain formation, since condensation rather than coalescence is a dominant growth process for most cloud droplets in this stage. During the late development stage, since most cloud droplets are involved in the collision and coalescence processes in the upper part of the cloud (Fig. $5 \mathrm{c}$ ), the size distributions of ammonium 5 sulfate particles have largely been changed after raindrops were produced (Fig. $5 \mathrm{~d}$ ). Ammonium sulfate masses inside water drops have been converted from small masses into large masses in the upper part of the cloud. We know that autoconversion is a process that rain embryos with diameters normally greater than $50 \mu \mathrm{m}$ initiate collisions to catch other cloud droplets to produce raindrops with diameters greater than their 10 threshold values. Since the condensation rate of each cloud droplet is inversely proportional to its radius, the water mass differences between cloud droplets in the same levels will get smaller and smaller after their nucleation, while their aerosol masses have been changed slowly and even remained unchanged if there are no collisions between them. On the other hand, the initial aerosol size distribution determines not only the potential concentration of cloud droplets but also that of rain embryos. The large aerosols will readily be the candidates of CCN to grow up to rain embryo sizes. Therefore, as for the aerosol size distribution of the case $\mathrm{E}_{1}$, a low number concentration of large aerosols contains a high mass concentration of aerosols even though the mass concentration of rain embryos may be relatively low (Fig. 6a and b). As a result, for each autoconversion coalescence process of rain embryos during the cloud developing stage, the ratio of the coagulated aerosol mass to the total aerosol mass of cloud droplets should be larger than the ratio of their coagulated water mass to the total water mass of the cloud droplets. Therefore, the ratios of $R_{\mathrm{a} \text {-auto }}$ to $R_{\mathrm{c} \text {-auto }}$ are much larger than 1.0 in the cloud (Fig. 4a) and the maximum ratio can reach 23.561 under the aerosol size distribution of $E_{1}$. The changes of this ratio in the different stages of the warm rain formation reflect the evolutions of both the cloud droplet spectra and the spectra of ammonium sulfate inside cloud droplets. Under the same atmospheric conditions, the evolution of the cloud droplet spectra is determined by the aeosol size distribution, which includes the aerosol concentration and the aerosol dis-

\section{ACPD}

13, 25481-25536, 2013

Aerosol conversion parameterizations in warm rain formation of cumulus clouds

J. Sun et al.

Title Page

Abstract Introduction

Conclusions

Tables References

Figures

14 -1

4

Back

Close 
tribution shape. Therefore, the initial aerosol size ditribution dominates the evolution of the ratio of $R_{\text {a-auto }}$ to $R_{\mathrm{c} \text {-auto }}$, which can even be less than 1.0 in the mature stage of the cloud with a low concentration of aerosols at the upper part of the cloud and in the developing stage of the cloud with an aerosol distribution shape different from the case of $E_{1}$. We will discuss these two scenarios in Sects. 8 and 9.

Accretion is a process that raindrops collide with cloud droplets to coalesce into larger raindrops. In contrast to autoconversion, a large number of cloud droplets with high water mass concentrations compared with low water mass concentrations of rain embryos will be converted into raindrops in the accretion processes (Fig. 6c), which 10 also means that a large number of cloud droplets with relatively low aerosol mass concentrations compared with high aerosol mass concentrations of rain embryos will be transferred into raindrops (Fig. 6d). As a result, the ratios of $R_{\mathrm{a} \text {-accre }}$ to $R_{\mathrm{c} \text {-accre }}$ are generally smaller than those of $R_{\text {a-auto }}$ to $R_{\mathrm{c} \text {-auto }}$. The maximum ratio of $R_{\text {a-accre }}$ to $R_{\mathrm{c} \text {-accre }}$ only reaches 1.83 in the simulation.

15 We noticed that the conversion ratios of $R_{\mathrm{a} \text {-conv }}$ to $R_{\mathrm{c} \text {-conv }}$ are far larger than 1.0 when the autoconversion process is a prevailing conversion process and are less than or around 1.0 when the accretion process is a predominant process and the autoconversion process can be negligible (Figs. 3a, $4 \mathrm{a}$ and c). A conversion ratio of $R_{\mathrm{a} \text {-conv }}$ to $R_{\mathrm{c} \text {-conv }}$ is determined by both of the ratio of $R_{\mathrm{a} \text {-auto }}$ to $R_{\mathrm{c} \text {-auto }}$ and the ratio of $R_{\mathrm{a} \text {-accre }}$ to $20 R_{\mathrm{c} \text {-accre }}$. By the definitions of these three kinds of conversion ratios, if the cloud droplet autoconversion rate $R_{\mathrm{c} \text {-auto }}$ is much larger than the cloud droplet accretion rate $R_{\mathrm{c} \text {-accre, }}$, the conversion ratio of $R_{\mathrm{a} \text {-conv }}$ to $R_{\mathrm{c} \text {-conv }}$ can be approximately expressed by the conversion ratio of $R_{\mathrm{a} \text {-auto }}$ to $R_{\mathrm{c} \text {-auto }}$; if the cloud droplet autoconversion rate $R_{\mathrm{c} \text {-auto }}$ is much smaller than the cloud droplet accretion rate $R_{\mathrm{c} \text {-accre }}$, the conversion ratio of $R_{\mathrm{a}-\mathrm{conv}}$ to

$25 R_{\mathrm{c}-\text { conv }}$ can be approximately expressed by the conversion ratio of $R_{\mathrm{a} \text {-accre }}$ to $R_{\mathrm{c} \text {-accre }}$. Therefore, the maximum ratio of $R_{\mathrm{a}-\mathrm{conv}}$ to $R_{\mathrm{c} \text {-conv }}$ can even reach 5.995 during the early developing stage with nearly the same value as that of $R_{\mathrm{a} \text {-auto }}$ to $R_{\mathrm{c} \text {-auto }}$.

\section{ACPD}

13, 25481-25536, 2013

Aerosol conversion parameterizations in warm rain formation of cumulus clouds

J. Sun et al.

Title Page
Abstract

Conclusions

Tables

14

4

Back
Introduction

References

Figures

- I

$>$

Close
Full Screen / Esc

Printer-friendly Version

Interactive Discussion 


\section{Parameterizations of ammonium sulfate conversions in the warm rain formation}

The precipitation production rates are normally determined by means of the autoconversion rates and the accretion rates in the bulk microphysics. As for the study of 5 aerosol conversions, the aerosol conversion rates are calculated through the precipitation production rates, the cloud water mass concentrations and the aerosol mass concentrations inside cloud droplets. Therefore, we need to find relationships between $R_{\mathrm{a}-\mathrm{conv} / \text { auto/accre }}$ and $R_{\mathrm{c} \text {-conv/auto/accre }}$ to determine the conversion rates of aerosols from cloud droplets to raindrops in the different conversion ways.

Figure 7a shows a relationship between $R_{\mathrm{a}-\mathrm{conv}}$ and $R_{\mathrm{c} \text {-conv }}$ in the warm rain formation by the complete coalescence approach. The maximum of $R_{\mathrm{a} \text {-conv }}$ is $0.0054 \mathrm{~s}^{-1}$. The maximum of $R_{\mathrm{c}-\mathrm{conv}}$ reaches $0.0035 \mathrm{~s}^{-1}$. The ratios of these two variables become far away from 1.0 when the ratios of the cloud droplet conversion rate to the cloud water mass concentration $\left(R_{\mathrm{c}-\mathrm{conv}}\right)$ are less than $1.0 \times 10^{-6} \mathrm{~s}^{-1}$ (Fig. $3 \mathrm{a}$ and b). $R_{\mathrm{a}-\mathrm{conv}}$ within 15 the whole domain of its variation can be expressed by $R_{\mathrm{c}-\mathrm{conv}}$ using a power regression function with a correlation coefficient of 0.9954 :

$R_{\mathrm{a}-\mathrm{conv}}=1.0390 R_{\mathrm{C}-\mathrm{conv}}^{0.9758}$

Note that the above regression function averages the large values and the small values of $R_{\mathrm{a}-\mathrm{conv}}$ when it is less than $1.0 \times 10^{-5} \mathrm{~s}^{-1}$, which means that the strong intensity of the aerosol conversion rate during the early developing stage of the cumulus cloud formation and the weak intensity of the aerosol conversion rate during the early precipitation stage will be adjusted by this regression equation.

Figure $7 \mathrm{~b}$ shows a relationship between $R_{\mathrm{a}-\mathrm{conv}}$ and $R_{\mathrm{c} \text {-conv }}$ in the warm rain formation by the partial coalescence approach for bulk microphysics parameterizations. $R_{\mathrm{a}-\mathrm{conv}}$ 25 can be expressed by $R_{\mathrm{c}-\mathrm{conv}}$ with a correlation coefficient of 0.9907 :

$$
R_{\mathrm{a}-\mathrm{conv}}=1.3698 R_{\mathrm{c}-\mathrm{conv}}^{0.9725}
$$

\section{ACPD}

13, 25481-25536, 2013

Aerosol conversion parameterizations in warm rain formation of cumulus clouds

J. Sun et al.

Title Page

Abstract Introduction

Conclusions

Tables

References

Figures

14

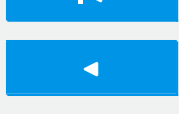

Back

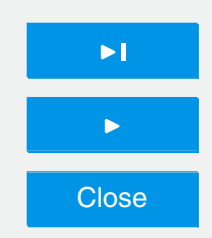

Full Screen / Esc

Printer-friendly Version

Interactive Discussion 
Comparing the above equation with the Eq. (10), the intensity of the aerosol conversion rate determined by the partial coalescence approach are slightly larger than those by the complete coalescence approach. The above regression equation can also be expressed by means of autoconversion and accretion separately. As for the autoconver5 sion process (Fig. 7c), $R_{\mathrm{a}-\text { auto }}$ can be expressed by $R_{\mathrm{c} \text {-auto }}$ with a correlation coefficient of 0.9768 :

$R_{\mathrm{a} \text {-auto }}=15.487 R_{\mathrm{c} \text {-auto }}^{1.093}$

The above regression equation indicates that the ratios of $R_{\mathrm{a} \text {-auto }}$ to $R_{\mathrm{c} \text {-auto }}$ are much larger than 1.0 when the intensity of the cloud water autoconversion rate $\left(R_{\mathrm{c} \text {-auto }}\right)$ be-

comes large. Correspondingly, as for the accretion process (Fig. $7 \mathrm{~d}$ ), $R_{\mathrm{a} \text {-accre }}$ can be expressed by $R_{\mathrm{c}-\text { accre }}$ with a correlation coefficient of 0.9996 :

$R_{\mathrm{a}-\mathrm{accre}}=1.1027 R_{\mathrm{c}-\mathrm{accre}}^{0.9888}$

Comparing Fig. 7c with Fig. 7d, the ratios of $R_{\mathrm{a} \text {-auto }}$ to $R_{\mathrm{c} \text {-auto }}$ are more dispersive than those of $R_{\mathrm{a} \text {-accre }}$ to $R_{\mathrm{c} \text {-accre }}$ even for the same intensity of the precipitation production 15 rate, which reflects a broad range of aerosol masses in the rain embryos.

\section{Sensitivity study of the effects of rain threshold radii on aerosol conversions}

Different threshold radii of raindrops even for the same evolution of cloud droplet spectra must result in different mass conversion rates of cloud droplets and of aerosols inside them. Therefore, it is necessary to study aerosol conversions under different

schemes of raindrop separation radii for bulk microphysics parameterizations. Note that such threshold-radius dependent conversions is also due to aerosol transfer from cloud droplets into raindrops in the stochastic collision and coalescence processes.

Figure 8 a shows the ratios of $R_{\text {a-conv }}$ to $R_{\text {c-conv }}$ with the threshold radius of $25 \mu \mathrm{m}$ by means of both the complete coalescence approach and the partial coalescence 25498
ACPD

13, 25481-25536, 2013

Aerosol conversion parameterizations in warm rain formation of cumulus clouds

J. Sun et al.

Title Page
Abstract

Conclusions

Tables

14

4

Back

Full Screen / Esc

Printer-friendly Version
Introduction

References

Figures

$>1$

Close 
approach. The maximum ratio of $R_{\mathrm{a}-\mathrm{conv}}$ to $R_{\mathrm{c}-\mathrm{conv}}$ is 17.451 by the partial coalescence approach. The large ratios of $R_{\mathrm{a} \text {-conv }}$ to $R_{\mathrm{c}-\mathrm{conv}}$ appear to occur at low altitudes in which the dominant conversion process should be autoconversion. These results indicate that the smaller threshold radius results in larger autoconversion rates of cloud droplets in 5 the early growth stage of cloud droplets around the cloud base. The ratios of $R_{\text {a-auto }}$ to $R_{\text {c-auto }}$ are also much larger than 1.0 in the cloud. The maximum ratio of $R_{\text {a-auto }}$ to $R_{\mathrm{c} \text {-auto }}$ reaches 29.037. Meanwhile, the maximum ratio of $R_{\mathrm{a} \text {-accre }}$ to $R_{\mathrm{c} \text {-accre }}$ only reaches 2.263. As far as we know, rain embryos are essential in the autoconversion process. The rain separation radius of $25 \mu \mathrm{m}$ leads to the radii of rain embryos to be 10 less than $25 \mu \mathrm{m}$, which means that collection efficiencies between rain embryos and small cloud droplets in such autoconversion processes become weak. The maximum autoconversion rate of cloud water reaches $0.0002 \mathrm{~g} \mathrm{~m}^{-3} \mathrm{~s}^{-1}$, which is less than that with the raindrop separation radius of $40 \mu \mathrm{m}$.

Figure 9 shows relationships between aerosol conversions and cloud water conver15 sions based on the raindrop separation radius of $25 \mu \mathrm{m}$. The linear regression equations are given in Table 3. The prominent feature of this scenario is that the ratios of $R_{\mathrm{a} \text {-auto }}$ to $R_{\mathrm{c} \text {-auto }}$ vary more dispersively, which is caused by a broad range of aerosol concentrations in rain embryos. Some rain embryos contain small aerosol mass concentrations while others contain large aerosol mass concentrations. As a result, the small rain separation radius results in a low regression coefficient for autoconversion and even weakens the regression coefficient for the combined conversion of autoconversion and accretion (Table 3).

Figure 10 a shows the ratios of $R_{\mathrm{a}-\text { conv }}$ to $R_{\mathrm{c} \text {-conv }}$ with the threshold radius of $50 \mu \mathrm{m}$. The large ratios of $R_{\mathrm{a}-\mathrm{conv}}$ to $R_{\mathrm{c} \text {-conv }}$ based on the complete coalescence approach only appear to occur at the early developing stage. The ratios of $R_{\text {a-auto }}$ to $R_{\mathrm{c} \text {-auto }}$ are normally larger than 1.0 in the cloud (Fig. 10b). But the maximum ratio of $R_{\mathrm{a} \text {-auto }}$ to $R_{\mathrm{c} \text {-auto }}$ is less than those with the low threshold radii. Correspondingly, the larger threshold radius results in higher regression coefficients for aerosol conversions (Fig. 11).
ACPD

13, 25481-25536, 2013

Aerosol conversion parameterizations in warm rain formation of cumulus clouds

J. Sun et al.

Title Page
Abstract

Conclusions

Tables

1

Back
Introduction

References

Figures

DI

Close
Full Screen / Esc

Printer-friendly Version

Interactive Discussion 
The above simulation results indicate that the threshold radius highly affects aerosol conversions. The low radius leads to high autoconversion rates for both of cloud droplets and aerosols at low altitudes above the cloud base in the developing stage of the cloud. However, the intensity of the aerosol mass conversion rate is larger than that 5 of the cloud water mass conversion rate at such places. On the other hand, the high threshold radius can reduce the maximum intensity of the aerosol mass conversion rate. Furthermore, the aerosol mass conversion rate becomes much more dependent on the cloud water mass conversion rate with the high threshold radius.

\section{Sensitivity study of the effects of aerosol concentrations on aerosol conversions}

The initial concentration of CCN will highly affect the spatial and temporal evolution of cloud droplet spectra (Sun et al., 2012a). The evolution of cloud droplet spectra is initially controlled by the condensation process and then predominantly regulated by the collision and coalescence processes. On the other hand, a fluctuation of the aerosol 15 number concentration may also result in a change of the aerosol mass distribution. Therefore, it is necessary to study aerosol conversions in response to a change of the aerosol concentration under the same aerosol distribution shape.

We simulated the warm rain formation under different number concentrations of ammonium sulfate (Table 2). The regression equations for various types of aerosol conversions are given in Tables 3 and 4 . The intensity of the aerosol conversion rate increases with an increase of the aerosol concentration (Table 3). The intensity of the aerosol accretion rate also increases with an increase of the aerosol concentration (Table 3). However, the intensity of the aerosol autoconversion rate increases with an increase of the aerosol number concentration and then decreases with a further increase of the aerosol number concentration. This phenomenon mainly results from the changes of the cloud droplet spectra due to aerosol concentration variations.
ACPD

13, 25481-25536, 2013

Aerosol conversion parameterizations in warm rain formation of cumulus clouds

J. Sun et al.

Title Page

Abstract Introduction

Conclusions

Tables References

Figures

14 -1

4

Back

Close 
Figure 12 shows the evolution of large cloud droplet concentrations and of ratios of $R_{\mathrm{a} \text {-auto }}$ to $R_{\mathrm{c} \text {-auto }}$ with the rain separation radius of $40 \mu \mathrm{m}$ in the simulations with different aerosol concentrations. We found that the ratios of $R_{\mathrm{a} \text {-auto }}$ to $R_{\mathrm{c} \text {-auto }}$ are highly related to the evolution of both the concentration of cloud droplets with diameters greater than

$525 \mu \mathrm{m}$ and the concentration of cloud droplets with diameters greater than $50 \mu \mathrm{m}$. As far as we know, an autoconversion process of cloud droplets with the rain threshold radius of $40 \mu \mathrm{m}$ involves a collision between a rain embryo with diameters greater than $40 \mu \mathrm{m}$ and a collected cloud droplet with diameters greater or less than $40 \mu \mathrm{m}$. For such collisions, the optimum coalescence occurs between a collector with diameters 10 greater than $50 \mu \mathrm{m}$ and a collected cloud droplet with diameters greater than $25 \mu \mathrm{m}$ (Hall, 1980). Therefore, the concentrations of cloud droplets with such sizes should affect the cloud droplet autoconversion and also the aerosol mass autoconversion. The concentration of cloud droplets with diameters greater than $25 \mu \mathrm{m}$ increases with an increase of the aerosol concentration and then decreases with a further increase of the aerosol concentration, which is highly related to the tendency of the ratio of $R_{\mathrm{a} \text {-auto }}$ to $R_{\text {c-auto }}$. However, the evolution of the ratio of $R_{\text {a-auto }}$ to $R_{\text {c-auto }}$ is directly determined by the evolution of both the cloud droplet mass spectra and of the aerosol mass spectra. Given the aerosol size distribution of $\mathrm{E}_{4}$ with a low concentration, the cloud droplet spectra will be rapidly broadened to large sizes. As a result, the mode diameter of the mass distribution of cloud droplets exceeds $50 \mu \mathrm{m}$ at the upper part of the cloud in the late developing stage. As a result, the ratios of $R_{\mathrm{a} \text {-auto }}$ to $R_{\mathrm{c} \text {-auto }}$ can be less than 1.0 (Fig. 12a), which is due to the mass concentration of coagulated drizzles occupying a high fraction of the total cloud droplet mass concentration while the mass concentration of coagulated aerosols occupying a relatively low fraction of the total aerosol mass concentration. Whereas, the high ratios of $R_{\mathrm{a} \text {-auto }}$ to $R_{\mathrm{c} \text {-auto }}$ appear in the early developing stage of the cloud since the mass concentration of coagulated drizzles takes a fraction of the total cloud droplet mass concentration to a low level, but the mass concentration of coagulated aerosols has a high fraction of the total aerosol mass concentration.
ACPD

13, 25481-25536, 2013

Aerosol conversion parameterizations in warm rain formation of cumulus clouds

J. Sun et al.

Title Page

Abstract Introduction

Conclusions

Tables

References

Figures

14

-1

4

Back

Close

Full Screen / Esc

Printer-friendly Version

Interactive Discussion 


\section{Sensitivity study of the effects of aerosol size distributions on aerosol conversions}

To simulate aerosol-cloud interaction with the bulk microphysics and then evaluate aerosol effects on precipitation, pollution and climate, it is necessary to establish a re5 lationship between the intensity of aerosol mass concentration conversion rate and the intensity of the conversion rate of the cloud droplet mass concentration under widelyemployed aerosol size distributions. The above modeling results show that the intensity of the aerosol mass concentration conversion rates is dependent on the evolution of both the cloud droplet mass spectra and the mass spectra of aerosols inside cloud droplets. The temporal and spatial evolution of the cloud droplet spectra is also highly regulated by the initial concentration of aerosols and their mass spectra. Therefore, not only aerosol concentrations but also aerosol distribution shapes should impact aerosol conversions. The numerical experiments for the different initial aerosol size distributions are essential to illustrate the effects of the aerosol size distribution on the warm

\subsection{The effects of aerosol size distributions on the warm rain formation}

Variation of the aerosol concentration with the same size distribution shape highly affects the evolution of the cloud droplet sepectra and then impacts the warm rain formation (Sun et al., 2012a). Figure 13 shows the evolution of the cloud liquid water content and of the rain water content in the simulations with the various aerosol size distributions. The warm rain formation has been delayed and the total precipitation amount decreases while the cloud liquid water content increases when the concentration of aerosols increases under the single log-normal size distributions with the same mean diameter and the same standard deviation (see Fig. 13a, b and e). Moreover, the different size distribution shapes even with the same aerosol concentration may also influence the warm rain formation. Comparing Fig. 13a with Fig. 13d for the same concentration of aerosols, we found that precipitation occurs earlier in the simulation with

\section{ACPD}

13, 25481-25536, 2013

Aerosol conversion parameterizations in warm rain formation of cumulus clouds

J. Sun et al.

Title Page

Abstract

Conclusions

Tables

14

4

Back

Full Screen / Esc

Printer-friendly Version

\section{Close}


the small geometric mean diameter than that with the large geometric mean diameter under an assumption that the geometric standard deviations of the two log-normal distributions are the same. Given the same geometric mean diameter, precipitation also occurs earlier in the simulation with the small geometric standard deviation than that 5 with the large geometric standard deviation (see Fig. 13b and c). Furthermore, the warm rain formation can be delayed not only in the simulation with the same aerosol concentration but also in the simulation with a lower aerosol concentration in which the geometric mean diameter of aerosols is larger than that of the aerosol size distributions with a higher aerosol concentration (comparing Fig. 13d with b and c). These results are all due to the different concentrations of cloud droplets to be nucleated even under the same condition of the initial aerosol concentration because the more aerosols will be activated if the concentration of the large aerosols becomes higher. Note that the high concentration of aerosols does not always mean that the low precipitation amount will be produced since the precipitation production rates highly depend on the total ac-

tivated aerosols, hence a higher concentration of aerosols can also result in a lower concentration of cloud droplets if their mean diameter and standard deviation are less than those of the aerosol size distributions even with relatively lower concentrations of aerosols (see Fig. 13e and h). Therefore, it is worth noting that aerosol distribution shapes can also impact the warm rain formation.

We need an alternative size distribution parameter, which can represent characteristics of the size distribution shape instead of the geometric mean diameter and the geometric standard deviation for studies of both the warm rain formation and the aerosol mass conversions. The mode diameter of the mass distribution for log-normal size distributions is a function of the geometric mean diameter and the geometric standard deviation. We derived the mode diameter of the mass distribution for log-normal size distributions (see Appendix). We further calculated the aerosol mode diameters of the mass distributions adopted in the simulations (Table 1). With aerosol concentrations increasing (see Fig. 13a, b and e), the warm rain formation has been delayed and the total precipitation amount decreases if the aerosol mode diameters of the mass distri-

\section{ACPD}

13, 25481-25536, 2013

Aerosol conversion parameterizations in warm rain formation of cumulus clouds

J. Sun et al.

Title Page
Abstract

Conclusions

Tables

14

4

Back
Introduction

References

Figures

$>1$

Close
Full Screen / Esc

Printer-friendly Version

Interactive Discussion 
butions are the same (Table 1). With aerosol mode diameters increasing (comparing Fig. 13a with $d$ and $c$ with $b$ ), the warm rain formation has been also delayed and the total precipitation amount decreases if aerosol concentrations are the same.

As for the trimodal aerosol distributions (Table 1), since there is no big difference 5 for the geometric mean diameters and the geometric standard deviations in the same mode of the trimodal aerosol distributions (Table 1), the aerosol concentration will dominate the speed of the warm rain formation (see Fig. 13f-i). The above results indicate that both the aerosol concentration and the aerosol distribution shape highly affect precipitation production rates.

\subsection{The effects of aerosol size distributions on aerosol conversions}

Different aerosol size distributions not only determine different precipitation production rates in the warm rain formation but also simultaneously lead to different aerosol mass concentration conversion rates. Since the evolution of mass distributions can reflect the speeds of mass conversions for both cloud droplets and aerosols, comparisons for their mass distributions may allow us to elucidate the rule of the mass conversions and also understand the dependence between aerosol mass conversions and precipitation production rates. Figure 14 shows the mass distributions of ammonium sulfate particles in the experimental simulations at $42.5 \mathrm{~min}$. Different initial aerosol size distributions result in different aerosol mass redistributions at the same time of the simulations. Figure 15 shows the mass distributions of water drops in the experimental simulations at the same time. The vertical locations of the new generated modes of the aerosol mass distributions match those of the mass distributions of water drops at the same time of the simulations. Different precipitation production rates obviously cause different aerosol conversion rates and then impact aerosol scavenging. Moreover, the precipitathe initial aerosol size distributions. Therefore, the relationship between the intensity of the aerosol mass concentration conversion rates and the intensity of the precipitation production rates should vary with different initial aerosol size distribtutions.

\section{ACPD}

13, 25481-25536, 2013

Aerosol conversion parameterizations in warm rain formation of cumulus clouds

J. Sun et al.

Title Page

Abstract Introduction

Conclusions

Tables References Figures

14 $\Delta \mathbf{I}$

4

Back Close 
Simulating with a single log-normal aerosol size distribution which only contains a nuclei mode with a relatively wide size range for cases of SM1, SM2 and SM5, we found that an increase of the aerosol concentration could also delay the aerosol scavenging (Fig. 14a, b and e) and the warm rain formation (Fig. 15a, b and e). Since such 5 a size distribution shape makes the aerosol mass of the distribution concentrated on the middle sizes of aerosols with a mode diameter of $0.25 \mu \mathrm{m}$, a low number concentration of large aerosols also contains a low mass concentration of aerosols. On the other hand, relatively low concentrations of aerosols accelerate the cloud droplet spectra broadening. The cloud droplet mode diameters of the mass distributions can even 10 exceed $50 \mu \mathrm{m}$ (Fig. 15a and b), which means the mass concentration of rain embryos occupy a high fraction of the total mass concentration of cloud droplets. Therefore, for each autoconversion coalescence process of rain embryos, the raio of the coagulated aerosol mass to the total aerosol mass of cloud droplets may be smaller than the ratio of their coagulated water mass to the total water mass of the cloud droplets. The ratios 15 of $R_{\mathrm{a} \text {-conv }}$ to $R_{\mathrm{c} \text {-conv }}$ are all less than 1.0 for the low aerosol concentration cases of SM1 and SM2 (Fig. 16a and b). Correspondingly, both the ratios of $R_{\mathrm{a} \text {-auto }}$ to $R_{\mathrm{c} \text {-auto }}$ and the ratios $R_{\mathrm{a} \text {-accre }}$ to $R_{\mathrm{c} \text {-accre }}$ are less than 1.0 (Table 4). A huge increase of the aerosol concentration can result in the ratios of $R_{\mathrm{a} \text {-conv }}$ to $R_{\mathrm{c} \text {-conv }}$ are greater than 1.0 when $R_{\mathrm{c} \text {-conv }}$ is less than $10^{-7} \mathrm{~s}^{-1}$ (Fig. 16e). Meanwhile, the ratios of $R_{\mathrm{a} \text {-auto }}$ to $R_{\mathrm{c} \text {-auto }}$ can exceed 20 1.0. These results indicate that the aerosol concentration increase can enhance the intensity of the aerosol mass concentration conversion rates for a single nuclei-mode distribution of aerosols.

Simulating with a narrow aerosol size range for the case of SM3, we found that the ratios of $R_{\mathrm{a} \text {-conv }}$ to $R_{\mathrm{c} \text {-conv }}$ are also less than 1.0 due to the large cloud droplet mode the mass distribution (Fig. 14c). Note that the relationship between $R_{\mathrm{a} \text {-conv }}$ to $R_{\mathrm{c} \text {-conv }}$ becomes stronger than that in the simulations with the large mode diameter of the aerosol mass distribution (Fig. 16c). These results further verify that the intensity of the aerosol mass concentration conversion rates is normally less than the intensity of the

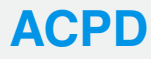

13, 25481-25536, 2013

Aerosol conversion parameterizations in warm rain formation of cumulus clouds

J. Sun et al.

Title Page

Abstract Introduction

Conclusions

References

Tables

Figures

14

DI

4

Back

$>$

Close

Printer-friendly Version

Interactive Discussion 
precipitation production rates under a single nuclei-mode distribution of aerosols with the exception in a huge concentration of aerosols. The lower mode diameter of the aerosol mass distribution will be utilized in the simulations for the warm rain formation, the higher the correlation between $R_{\mathrm{a} \text {-conv/auto/accre }}$ to $R_{\mathrm{c}-\text { conv/auto/accre }}$ we will obtain.

$5 \quad$ Simulating with a single accumulation-mode aerosol size distribution of the case SM4, which has the same aerosol concentration as the case SM1, we found that the large aerosol mode diameter of the mass distribution causes relatively higher concentrations of cloud droplets to be activated than those in the simulation of the case SM1 with the small aerosol mode diameter (comparing Fig. 14a and d). The large cloud

droplet mode diameter at the cloud top can also result in the ratios of $R_{\mathrm{a}-\text { conv }}$ to $R_{\mathrm{c} \text {-conv }}$ less than 1.0. However, the small cloud droplet mode diameter in the most part of the cloud and the large aerosol mode diameter both lead to the ratios of $R_{\mathrm{a} \text {-conv }}$ to $R_{\mathrm{c} \text {-conv }}$ greater than 1.0 in the early developing stage of the warm rain formation (Fig. 16d). Therefore, the ratios of $R_{\mathrm{a}-\mathrm{conv}}$ to $R_{\mathrm{c} \text {-conv }}$ becomes more dispersive and their regression ter of the mass distribution highly affects the warm rain formation and the aerosol mass conversions even under low aerosol number concentrations.

As far as trimodal aerosol distributions are concerned, since the combined mode diameters of the aerosol mass distributions also depend on the number concentration of aerosols in each mode (Fig. 14f-i), both the combined mode diameter and the total number concentration of aerosols affect the warm rain formation and the aerosol conversions. As for a large combined single-mode diameter and a low number concentration of the case TM1-M (Fig. 14f), the cloud droplet spectra will be readily broadened to large sizes at the upper part of the cloud (Fig. 15f). As a result, the ratios of $R_{\mathrm{a} \text {-conv }}$ to $R_{\mathrm{c}-\mathrm{conv}}$ are less than 1.0 in such places where $R_{\mathrm{c}-\mathrm{conv}}$ is larger than $10^{-6} \mathrm{~s}^{-1}$ (Fig. 16f).

Comparing Fig. 14d and $\mathrm{f}$, we found that the large single-mode diameter of the aerosol mass distribution with a relatively high concentration of aerosols results in the warm rain formation more rapidly than the small mode diameter of the mass distribution does even with a low concentration of aerosols, which means that the low concentra-
ACPD

13, 25481-25536, 2013

Aerosol conversion parameterizations in warm rain formation of cumulus clouds

J. Sun et al.

Title Page

Abstract Introduction

Conclusions

Tables References

Figures

14 -1

4

Back

Close

Full Screen / Esc

Printer-friendly Version

Interactive Discussion 
tion of cloud droplets will be activated if the largest-mean-diameter mode dominates the combined mode of the aerosol mass distribution. These results further indicate that the warm rain formation favours the aerosol size distributions with both the small and large single-narrow mode diameters of the mass distributions, such as the cases with 5 a diameter less than $0.1 \mu \mathrm{m}$ (Fig. 14c) or greater than $10.0 \mu \mathrm{m}$ (Fig. 14f).

Moreover, if the combined aerosol mass distributions have double modes or one largely broadened mode, such as the cases of TM1-C and TM1-B (Fig. 14g and f), the cloud droplet spectra will be narrow and the warm rain formation will be delayed (Fig. $15 \mathrm{~g}$ and f). The narrow cloud droplet spectra in the early developing stage of 10 the cloud lead to the ratios of $R_{\mathrm{a}-\mathrm{conv}}$ to $R_{\mathrm{c}-\mathrm{conv}}$ far larger than 1.0 (Fig. $16 \mathrm{~g}$ and f). Furthermore, the extremely narrow cloud droplet spectra resulting from an extraordinary aerosol concentration may cause precipitation not to occur (Fig. 13i), such as the case of TM1-U. Both the single median-diameter mode of the aerosol mass distribution (Fig. 14i) and the narrow cloud droplet spectra (Fig. 15i) cause the ratios of $R_{\mathrm{a}-\mathrm{conv}}$ to $15 R_{\mathrm{c}-\text { conv }}$ to become more dispersive (Fig. 16i).

\section{Discussions and conclusions}

We used an aerosol and cloud interaction model with the bin microphysics to study the aerosol mass conversions from inside cloud droplets into inside raindrops, which have been defined by the different threshold rain radii in the bulk microphysics. The water

drop spectra have commonly been separated into the cloud droplet spectra and the raindrop spectra for the calculation simplicity in the bulk microphysics. The autoconversion and accretion processes therefore have been applied to characterize the formation and the growth of raindrops. The speed of the warm rain formation depends on both the autoconversion rate and accretion rate of cloud droplets. The mass concentration con-

verson rates aerosols from inside cloud droplets into inside raindrops have usually been scaled by the autoconversion rates and accretion rates of cloud droplets. Such approaches to determine the precipitation production rates and aerosol mass concen-

\section{ACPD}

13, 25481-25536, 2013

Aerosol conversion parameterizations in warm rain formation of cumulus clouds

J. Sun et al.

Title Page
Abstract

Conclusions

Tables

14

4

Back
Introduction

References

Figures

DI

Close
Full Screen / Esc

Printer-friendly Version

Interactive Discussion 
tration conversion rates in the bulk microphysics must have some descrepancies from those to be calculated with the bin microphysics. Such descrepancies may come from the methodology of the precipitation production rates themselves, the schemes of the precipiation production rates in the bulk microphysics and the present approach to de5 termine the aerosol mass conversions. Therefore, we evaluated the differences in the conversion rates for both cloud droplets and aerosols between the complete coalescence approach concerning the stochastic collision and coalescence processes and the partial coalescence approach regarding the predefined rain formation processes according to the definition in the bulk microphysics. We further parameterized the 10 aerosol mass concentration conversions considering different aerosol concentrations and different aerosol size distributions.

In the bulk microphysics, since the mass distribution of water drops has always been considered to be composed of two modes, which represent cloud droplets and raindrops, respectively, the collection processes of water drops consist of the relatively independent processes of autoconversion, accretion, cloud-droplet self-collection and raindrop self-collection (Beheng and Doms, 1986; Beheng, 1994; Seifert and Beheng, 2001) or the relatively independent processes of accretion and self-collection in which autoconversion is included (Cohard and Pinty, 2000). However, the collection processes of water drops should be viewed as a result of random collisions for the evolution of an entire droplet spectrum rather than as the growth of a subset of drops (Rogers and Yau, 1989). Therefore, both the intensity of the precipitation production rate and the intensity of the aerosol mass concentration conversion rate are different between the complete coalescence approach and the partial coalescece approach. Our study showed that the intensity of the precipitation production rate with the latter approach is slightly overestimated at the early developing stage, and also the intensity of the aerosol conversion rate is slightly overestimated in the whole process of the warm rain formation. Furthermore, the intensity of the aerosol mass concentration conversion rate cannot be the same as the intensity of the precipitation production rate.
ACPD

13, 25481-25536, 2013

Aerosol conversion parameterizations in warm rain formation of cumulus clouds

J. Sun et al.

Title Page

Abstract Introduction

Conclusions

Tables References

Figures

14 -1

4

Back

Close 
The intensity of the aerosol mass concentration conversion rate depends on the intensity of the precipitation production rate. Such a dependence varies with the threshold radius of raindrops and the aerosol size distribution, which includes the aerosol number concentration and the aerosol size distribution shape. The intensity of the pre5 cipitation production rate itself depends on the evolution of the mass spectra of water drops. The threshold radius of raindrops divides the mass spectra of water drops into the mass spectra of cloud droplets and the mass spectra of raindrops. The intensity of the autoconversion rate of cloud droplets directly relys on the evolution of the mass spectra of cloud droplets. The intensity of the accretion rate of cloud droplets depends on the evolution of the mass spectra of both cloud droplets and raindrops. The evolution of the mass spectra of cloud droplets is mainly determined by the concentration of cloud droplets to be activated. In other words, both the concentration and the size distribution shape of aerosols dominate the intensity of the precipitation production rate. The intensity of the aerosol mass concentration conversion rate reflects the evolution of the aerosol mass spectra, which can change when the coalescence of water drops occurs. Both the intensity of the aerosol autoconversion rate and the intensity of the aerosol accretion rate are directly related to the evolution of the mass spectra of aerosols only inside cloud droplets, which is regulated by the intensity of the autoconversion rate of cloud droplets and the intensity of the accretion rate of cloud droplets for a specific initial mass spectra of aerosols for the lognormal size distributions of ambient aerosols, respectively.

The initial mass spectra of aerosols not only affect the intensity of the aerosol mass concentration conversion rate and the intensity of precipitation production rate but also impact the ratio between them. Since the large cloud droplets can be the candidates of rain embryos to trigger the autoconversion process, the larger the mode diameter of the initial mass spectra of aerosols is, the higher the intensity of the aerosol mass concentration autoconversion rate becomes. Under such a scenario, the higher cloud droplet concentration will be nucleated and the mode diameter of the mass spectra of cloud droplets becomes smaller. As a result, the intensity of the autoconversion rate

\section{ACPD}

13, 25481-25536, 2013

Aerosol conversion parameterizations in warm rain formation of cumulus clouds

J. Sun et al.

Title Page
Abstract

Conclusions

Tables

14

4

Back

Full Screen / Esc
Printer-friendly Version

Interactive Discussion 
of cloud droplets becomes weaker, and the ratio of the intensity of the aerosol mass concentration conversion rate to the intensity of precipitation production rate may get much larger than 1.0. On the contrary, the smaller the mode diameter of the initial mass spectra of aerosols is, the lower the intensity of the aerosol mass concentration autoconversion rate becomes. Under such a scenario, the lower cloud droplet concentration will be nucleated and the mode diameter of the mass spectra of cloud droplets becomes larger. Consequently, the intensity of the autoconversion rate of cloud droplets becomes larger, and the ratio of the intensity of the aerosol mass concentration conversion rate to the intensity of precipitation production rate even gets less than 1.0. 10 Therefore, the mode diameter of the initial mass spectra of aerosols should dominate the relationship between the intensity of the aerosol mass concentration conversion rate and the intensity of precipitation production rate.

Moreover, the threshold rain radius itself arbitrarily determines the onset of the autoconversion process. The dependence of the intensity of the aerosol mass concentration conversion rate on the intensity of precipitation production rate would be weakened if the small threshold rain radius were implemented in the bulk microphysics. Since the concentration of aerosols directly affects the concentration of cloud droplets to be nucleated, the mode diameter of the mass spectra of cloud droplets decreases with an increase of the concentration of aerosols. Therefore, the ratio of the intensity of the aerosol mass concentration autoconversion rate to the intensity of cloud droplet autoconversion rate should also increase provided that the autoconversion rate of cloud droplets does not decrease, hence a remarkble decrease of the concentration of large cloud droplets due to a largely increased aerosol concentration can absolutely result in that ratio to become small. Furthermore, since the cloud droplet spectra vary with the different developing stages and the different altitudes of the clouds, the ratio of $R_{\text {a-auto }}$ to $R_{\text {c-auto }}$ may change sharply. On the contrary, since the accretion rate of cloud droplets is less dependent on the mode diameter of the mass distribution of cloud droplets, the ratio of $R_{\mathrm{a} \text {-accre }}$ to $R_{\mathrm{c} \text {-accre }}$ is normally close to 1.0 , and $R_{\mathrm{a} \text {-accre }}$ is much more dependent on $R_{\mathrm{c} \text {-accre }}$.

\section{ACPD}

13, 25481-25536, 2013

Aerosol conversion parameterizations in warm rain formation of cumulus clouds

J. Sun et al.

Title Page

Abstract

Conclusions

Tables

14

4

Back

Full Screen / Esc

Printer-friendly Version 
Application of the above aerosol conversion rules during the precipitation production processes into any cloud-aerosol interaction models should result in the coincidence of the high aerosol mass concentration with the high rain water content at the early precipitation stage. In order to reflect this property of the aerosol wet removal in the warm 5 rain formation for the bulk microphysics parameterizations, the aerosol mass conversion parameterizations are necessary to be developed. Some regression equations for aerosol mass conversions have been established and may represent the aerosol mass conversion rules under different aerosol size distributions. These parameterizations can be applied into climate models, air pollution models and mesoscale models, all of 10 which involve the precipitation production and the aerosol scavenging to study the issues related to aerosol topics. Furthermore, the updraft velocities and supersaturations both should be explicitly determined in those models rather than some models with the certain assumed values. However, the adopted scheme of the precipitation production rates in the bulk microphysics is another important factor to impact the aerosol wet removal. Hence, comparing the current bulk microphysics parameterizations for the precipitation production rates with the bin microphysics by means of this cloud-aerosol interaction model will be done in future.

\section{Appendix A}

\section{Mode diameter of the mass distribution for the log-normal distribution}

20 We assumed that one particle distribution to consider adopting is the log-normal distribution:

$f(\ln D)=\frac{\mathrm{d} N}{\mathrm{~d} \ln D}=\frac{N_{0}}{\sqrt{2 \pi} \ln \sigma} e^{\left(-\frac{1}{2}\left(\frac{\ln \left(D / D_{\mathrm{g}}\right)}{\ln \sigma}\right)^{2}\right)}$

\section{ACPD}

13, 25481-25536, 2013

Aerosol conversion parameterizations in warm rain formation of cumulus clouds

J. Sun et al.

Title Page
Abstract

Conclusions

Tables

14

4

Back
Introduction

References

Figures

$\Delta$

Close
Full Screen / Esc

Printer-friendly Version

Interactive Discussion 
where $f$ is the log-normal size distribution function, $N$ is the concentration of particles, $D$ is the diameter of particles, $\sigma$ is the geometric standard deviation, $D_{\mathrm{g}}$ is the geometric mean diameter, $N_{0}$ is the total number of particles per unit volume.

We can get the mass distribution as follows:

${ }_{5} g(\ln D)=\frac{\mathrm{d} M}{\mathrm{~d} \ln D}=\sqrt{\frac{\pi}{2}} \frac{\rho N_{0} D^{3}}{6 \ln \sigma} e^{\left(-\frac{1}{2}\left(\frac{\ln \left(D / D_{\mathrm{g}}\right)}{\ln \sigma}\right)^{2}\right)}$

where $g$ is the mass distribution function, $M$ is the mass concentration of particles, $\rho$ is the density of particles.

The mode diameter of the mass distribution should satisfy:

$\frac{\partial \ln (g(\ln D))}{\partial \ln D}=0$

10 We can obtain the mode diameter $D_{\mathrm{m}}$ :

$D_{\mathrm{m}}=D_{\mathrm{g}} e^{3(\ln \sigma)^{2}}$

Acknowledgements. We appreciate financial support from the Natural Science and Engineering Research Council of Canada (NSERC), initial financial support from Institute of Atmospheric Physics, Chinese Academy of Sciences for "100 Talents program of the Chinese Academy of 15 Sciences", and National Natural Science Foundation of China (No:40905015, 41275147).

\section{References}

Ackerman, A. S., Toon, O. B., and Hobbs, P. V.: A model for particle microphysics, turbulent mixing, and radiative transfer in the statocumulus-topped marine boundary layer and comparisons woth measurements, J. Atmos. Sci., 52, 1204-1236, 1995. 25483

20 Baker, M. B.: Variability in the concentrations of cloud condensations nuclei in the marine cloudtopped boundary layer, Tellus, 45, 458-472, 1993. 25484

Aerosol conversion parameterizations in warm rain formation of cumulus clouds

J. Sun et al.

Title Page

Abstract

Conclusions

Tables

14

4

Back
Introduction

References

Figures

$>1$

Close

Full Screen / Esc

Printer-friendly Version

Interactive Discussion 
Beard, K. V.: Experimental and numerical collision efficiencies for submicron particles scavenged by small raindrops, J. Atmos. Sci., 31, 1595-1603, 1974. 25489

Beard, K. V. and Ochs, H. T.: Warm-rain initiation: an overview of microphysical mechanisms, J. Appl. Meteorol., 32, 608-625, 1993. 25489

5 Beheng, K. D.: A parameterization of warm cloud microphysical conversion processes, Atmos. Res., 33, 193-206, 1994. 25484, 25485, 25508

Beheng, K. D. and Doms, G.: A general formulation of collection rates of cloud and raindrops using the kinetic equation and comparison with parameterizations, Beitr. Phys. Atmos., 59, 66-84, 1986. 25485, 25508

10 Berry, E. X.: Modification of the warm rain process, Preprints 1st Nat. Conf. Weather Modification, American Meteorological Society, Albany, 1968. 25484

Berry, E. X. and Reinhardt, R. L.: An analysis of cloud drop growth by collection: Part 2. Single initial distributions, J. Atmos. Sci., 31, 1825-1831, 1974. 25485

Bott, A.: A flux method for the numerical solution of the stochastic colllection equation: extension

15 to two-dimensional particle distributions, J. Atmos. Sci., 57, 284-294, 2000. 25488

Chen, J. and Lamb, D.: Simulation of cloud microphysical and chemical processes using a multicomponent framework. Part 1: Description of the micrphysical model, J. Atmos. Sci., 51, 2613-2630, 1994. 25483

Cohard, J. and Pinty, J.: A comprehensive two-moment warm microphysical bulk scheme. Part

20 1: Description and tests, Q. J. Roy. Meteorol. Soc., 126, 1815-1842, 2000. 25484, 25485, 25508

Cotton, W. R. and Anthes, R. A.: Storm and Cloud Dynamics, Academic Press, San Diego, 1989. 25484

Croft, B., Lohmann, U., Martin, R. V., Stier, P., Wurzler, S., Feichter, J., Hoose, C., Heikkilä, U., van Donkelaar, A., and Ferrachat, S.: Influences of in-cloud aerosol scavenging parameterizations on aerosol concentrations and wet deposition in ECHAM5-HAM, Atmos. Chem. Phys., 10, 1511-1543, doi:10.5194/acp-10-1511-2010, 2010. 25483

Feingold, G., Kreidenweis, S. M., Stevens, B., and Cotton, W. R.: Numerical simulations of stratocumulus processing of cloud condensation nuclei through collision-coalescence, J. Geo30 phys. Res., 101, 21391-21402, 1996. 25483

Fitzgerald, J. W.: Marine aerosols: a review, Atmos. Environ., 25, 533-545, 1991. 25490

Flossmann, A. I., Hall, W. D., and Pruppacher, H. R.: A theoretical study of the wet removal of atmospheric pollutants. Part 1: The redistribution of aerosol particles captured through

Aerosol conversion

parameterizations in

warm rain formation

of cumulus clouds

J. Sun et al.

Title Page

Abstract

Introduction

Conclusions

Tables

References

Figures

14

4

Back

Close

Full Screen / Esc

Printer-friendly Version

Interactive Discussion

(n)

rion


nucleation and impaction scavenging by growing cloud drops, J. Atmos. Sci., 42, 583-606, 1985. 25483, 25491

Franklin, C. N.: A warm rain microphysics parameterization that includes the effect of turbulence, J. Atmos. Sci., 57, 1795-1816, 2008. 25485

5 Gong, W., Bouchet, V. S., Makar, P. A., Moran, M. D., Gong, S., and Leaitch, W. R.: Cloud processing of gases and aerosols in a regional air quality model (AURAMS): evaluation against aircraft data, Earth. Environ. Sci, 6, 553-561, 2007. 25483

Hall, W. D.: A detail microphysical model within a two-dimensional dynamic framework: model description and preliminary results, J. Atmos. Sci., 37, 2486-2507, 1980. 25489, 25490, $10 \quad 25501$

Ivanova, I. T. and Leighton, H. G.: Aerosol-cloud interactions in a mesoscale model. Part 1: Sensitivity to activation and collision-coalescence, J. Atmos. Sci., 65, 289-308, 2008. 25483

Junge, C. E. and Gustafson, P. E.: On the distribution of sea salt over the United States and its removal by precipitation, Tellus, 9, 164-173, 1957. 25483

15 Kazil, J., Wang, H., Feingold, G., Clarke, A. D., Snider, J. R., and Bandy, A. R.: Modeling chemical and aerosol processes in the transition from closed to open cells during VOCALSREx, Atmos. Chem. Phys., 11, 7491-7514, doi:10.5194/acp-11-7491-2011, 2011. 25483

Kessler, E.: On the distribution and continuity of water substance in atmospheric circulation, Meteorol. Monogr., 32, American Meteorological Society, Boston, Mass., 84 pp., 1969. 25484, 25485

Khairoutdinov, M. and Kogan, U.: A new cloud physics parameterization in a large-eddy simulation model of marine stratocumulus, Mon. Weather Rev., 128, 229-243, 2000. 25484, 25485

Klett, J. D. and Davis, M. H.: Theoretical collision efficiencies of cloud droplets at small Reynolds 25 numbers, J. Atmos. Sci., 30, 107-117, 1973. 25490

Kogan, Y.: A cumulus cloud microphysics parameterization for cloud-resolving models, J. Atmos. Sci., 70, 1423-1436, 2013. 25485

Kogan, Y. L., Khairoutdinov, M. P., Lilly, D. K., Kogan, Z. N., and Liu, Q.: Modeling of stratocumulus cloud layers in a large eddy simulation model with explicit microphysics, J. Atmos. Sci., $30 \quad$ 52, 2923-2940, 1995. 25483

Koziol, A. S. and Leighton, H. G.: The moments method for multi-modal multi-component aerosols as applied to the coagulation-type equation, Q. J. Roy. Meteorol. Soc., 133, 121, 2007. 25489

Aerosol conversion

parameterizations in

warm rain formation

of cumulus clouds

J. Sun et al.

Title Page

Abstract

Introduction

Conclusions

Tables

References

Figures

14

4

Back

Close

Full Screen / Esc

Printer-friendly Version

Interactive Discussion ose 
Lebo, Z. J. and Seinfeld, J. H.: Theoretical basis for convective invigoration due to increased aerosol concentration, Atmos. Chem. Phys., 11, 5407-5429, doi:10.5194/acp-11-5407-2011, 2011. 25483

Liu, X. and Wang, M.: A parameterization of the efficiency of nucleation scavenging of aerosol particles and some related physicochemical factors, Atmos. Environ., 30, 2335-2341, 1996. 25483

Liu, Y. and Daum, P. H.: Parameterization of the autoconversion porcess. Part 1: Analytical formulation of the Kessler-type parameterizations, J. Atmos. Sci., 61, 1539-1548, 2004. 25484

Manton, M. J. and Cotton, W. R.: Formulation of approximate equations for modeling moist deep convection on the mesoscale, Atmos. Sci. Pap., 266, Colorado State Univ., Fort Collins, Colo., 62 pp., 1977. 25484

Monier, M., Wobrock, W., Gayet, J.-F., and Flossmann, A.: Development of a detailed microphysics cirrus model for the recent INCA campaign, J. Atmos. Sci., 63, 504-525, 2006. 25489

Nenes, A. and Seinfeld, J. H.: Parameterization of cloud droplet formation in global climate models, J. Geophys. Res., 108, 4415, doi:10.1029/2002JD002911, 2003. 25490, 25521

O'Dowd, C. D., Smith, M. H., Consterdine, I. E., and Lowe, J. A.: Marine aerosol, sea salt, and the marine sulphur cycle: a short review, Atmos. Environ., 37, 73-80, 1997. 25490

Orville, H. D. and Kopp, F. J.: Numerical simulation of the history of a hailstorm, J. Atmos. Sci., 34, 1596-1618, 1977. 25485

Ovchinnikov, M. and Easter, R. C.: Modeling aerosol growth by aqueous chemistry in a nonprecipitating stratiform cloud, J. Geophys. Res., 115, D14210, doi:10.1029/2009JD012816, 2010. 25483

Pflaum, J. C. and Pruppacher, H. R.: A wind tunnel investigation of the growth of graupel initiated from frozen drops, J. Atmos. Sci., 57, 680-689, 1979. 25489

Pruppacher, P. S. and Klett, J. D.: Microphysics of Clouds and Precipitation, Kluwer Academic, Dordrecht, 1997. 25484, 25485

Rogers, R. R. and Yau, M. K.: A Short Course in Cloud Physics, Pergamon Press, Oxford, England, 1989. 25508

30 Rotstayn, L. D.: A physically based scheme for the treatment of stratiform clouds and precipitation in large-scale models. Part 1: Description and evaluation of the microphsical processes, Q. J. Roy. Meteorol. Soc., 123, 1227-1282, 1997. 25484

\section{ACPD}

13, 25481-25536, 2013

Aerosol conversion parameterizations in warm rain formation of cumulus clouds

J. Sun et al.

Title Page

Abstract

Introduction

Conclusions

References

Tables

Figures

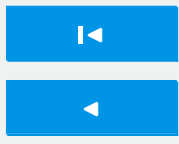

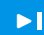

$>$

Back

Close 
Schumann, T.: Aerosol and hydrometeor concentrations and their chemical composition during winter precipitation along a mountain slope. Part 3: Size-differentiated in-cloud scavenging efficiencies, Atmos. Environ., 25, 809-824, 1991. 25482

Seifert, A. and Beheng, K. D.: A double-moment parameterization for simulating autoconversion, accretion and selfcollection, Atmos. Res., 60, 265-281, 2001. 25484, 25485, 25508

Sun, J., Ariya, P. A., Leighton, H. G., and Yau, M. K.: Modelling study of ice formation in warmbased precipitating shallow cumulus clouds, J. Atmos. Sci., 69, 3315-3335, 2012a. 25488, 25490, 25491, 25500, 25502, 25521

Sun, J., Leighton, H., Yau, M. K., and Ariya, P.: Numerical evidence for cloud droplet nucleation at the cloud-environment interface, Atmos. Chem. Phys., 12, 12155-12164, doi:10.5194/acp12-12155-2012, 2012b. 25494

Vakkari, V., Beukes, J. P., Laakso, H., Mabaso, D., Pienaar, J. J., Kulmala, M., and Laakso, L.: Long-term observations of aerosol size distributions in semi-clean and polluted savannah in South Africa, Atmos. Chem. Phys., 13, 1751-1770, doi:10.5194/acp-13-1751-2013, 2013. 25490

Whitby, K.: The physical charateristics of sulfur aerosols, Atmos. Environ., 12, 135-159, 1978. 25490, 25521

Wisner, C. H. D. and Myers, C.: A numerical model of a hail-bearing cloud, J. Atmos. Sci., 29, 1160-1181, 1972. 25485

20 Wood, R. and Blossey, P. N.: Comments on "Parameterization of the autoconversion process. Part 1: Analytical formulation of the Kessler-type parameterizations", J. Atmos. Sci., 62, 3003-3006, 2005. 25484

Xue, L., Teller, A., Rasmussen, R., Geresdi, I., and Pan, Z.: Effects of aerosol solubility and regeneration on warm-phase orographic clouds and precipitation simulated by a detailed bin microphysical scheme, J. Atmos. Sci., 67, 3336-3354, 2010. 25483

Yau, M. K.: A two-cylinder model of cumulus cells and its application in computing cumulus transports, J. Atmos. Sci., 37, 2470-2485, 1980. 25491

\section{ACPD}

13, 25481-25536, 2013

Aerosol conversion parameterizations in warm rain formation of cumulus clouds

J. Sun et al.

Title Page

Abstract

Introduction

Conclusions

References

Tables

Figures

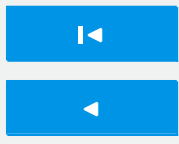

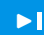

Back

Close

Full Screen / Esc

Printer-friendly Version

Interactive Discussion 


\section{ACPD}

13, 25481-25536, 2013

Aerosol conversion parameterizations in warm rain formation

Table 1. Size distribution parameters for experimental simulations $(N$ : number concentration in $\mathrm{cm}^{-3} ; D_{\mathrm{g}}$ : mean diameter in $\mu \mathrm{m} ; \sigma$ : standard deviation); $D_{\mathrm{m}}$ : mode diameter of the mass distribution. The plot of the aerosol size distributions is given in Fig. 1.

\begin{tabular}{|c|c|c|c|c|c|c|c|c|c|c|c|c|}
\hline \multirow[b]{2}{*}{ Test case } & \multicolumn{4}{|c|}{ Mode 1} & \multicolumn{4}{|c|}{ Mode 2} & \multicolumn{4}{|c|}{ Mode 3} \\
\hline & $N_{1}$ & $D_{\mathrm{g}, 1}$ & $\sigma_{1}$ & $D_{\mathrm{m}, 1}$ & $N_{2}$ & $D_{\mathrm{g}, 2}$ & $\sigma_{2}$ & $D_{\mathrm{m}, 1}$ & $N_{3}$ & $D_{\mathrm{g}, 3}$ & $\sigma_{3}$ & $D_{\mathrm{m}, 1}$ \\
\hline $\mathrm{E}_{4}$ & 133 & 0.06 & 1.9 & 0.21 & 70 & 0.2 & 1.9 & 0.69 & 3 & 2 & 2.0 & 8.45 \\
\hline $\mathrm{SM}_{1}$ & 200 & 0.02 & 2.5 & 0.25 & & & & & & & & \\
\hline $\mathrm{SM}_{2}$ & 1000 & 0.02 & 2.5 & 0.25 & & & & & & & & \\
\hline $\mathrm{SM}_{3}$ & 1000 & 0.02 & 1.5 & 0.03 & & & & & & & & \\
\hline $\mathrm{SM}_{4}$ & 200 & 0.2 & 2.5 & 2.48 & & & & & & & & \\
\hline $\mathrm{SM}_{5}^{4}$ & 10000 & 0.02 & 2.5 & 0.25 & & & & & & & & \\
\hline TM1-M & 340 & 0.010 & 1.6 & 0.02 & 60 & 0.070 & 2.0 & 0.30 & 3.1 & 0.62 & 2.7 & 11.96 \\
\hline TM1-C & 1000 & 0.016 & 1.6 & 0.03 & 800 & 0.068 & 2.1 & 0.35 & 0.72 & 0.92 & 2.2 & 5.94 \\
\hline TM1-B & 6400 & 0.016 & 1.7 & 0.04 & 2300 & 0.076 & 2.0 & 0.32 & 3.2 & 1.02 & 2.16 & 6.04 \\
\hline TM1-U & 106000 & 0.014 & 1.8 & 0.04 & 32000 & 0.054 & 2.16 & 0.32 & 5.4 & 0.86 & 2.21 & 5.67 \\
\hline
\end{tabular}

of cumulus clouds

J. Sun et al.

Title Page

Abstract

Introduction

Conclusions

References

Tables

Figures

14

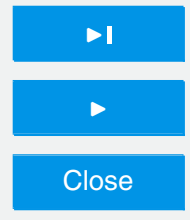

Back

Full Screen / Esc

Printer-friendly Version

Interactive Discussion 
Table 2. Experimental simulations for different threshold radii of raindrops, different aerosol concentrations and different aerosol size distributions.

\begin{tabular}{lcc}
\hline Case & Concentration of aerosols $\left(\mathrm{cm}^{-3}\right)$ & Threshold radius of raindrops $(\mu \mathrm{m})$ \\
\hline$E_{1}$ & $6 \times 217$ & $40 \mu \mathrm{m}$ \\
$E_{2}$ & $6 \times 217$ & $25 \mu \mathrm{m}$ \\
$E_{3}$ & $6 \times 217$ & $50 \mu \mathrm{m}$ \\
$E_{4}$ & 217 & $40 \mu \mathrm{m}$ \\
$E_{5}$ & $3 \times 217$ & $40 \mu \mathrm{m}$ \\
$E_{6}$ & $12 \times 217$ & $40 \mu \mathrm{m}$ \\
$E_{7}$ & $24 \times 217$ & $40 \mu \mathrm{m}$ \\
SM1 & 200 & $40 \mu \mathrm{m}$ \\
SM2 & 1000 & $40 \mu \mathrm{m}$ \\
SM3 & 1000 & $40 \mu \mathrm{m}$ \\
SM4 & 200 & $40 \mu \mathrm{m}$ \\
SM5 & 10000 & $40 \mu \mathrm{m}$ \\
TM1-M & 403 & $40 \mu \mathrm{m}$ \\
TM1-C & 1800 & $40 \mu \mathrm{m}$ \\
TM1-B & 8703 & $40 \mu \mathrm{m}$ \\
TM1-U & 138005 & $40 \mu \mathrm{m}$ \\
\hline
\end{tabular}

13, 25481-25536, 2013

Aerosol conversion parameterizations in warm rain formation of cumulus clouds

J. Sun et al.

Title Page

Abstract

Introduction

Conclusions

References

Tables

Figures
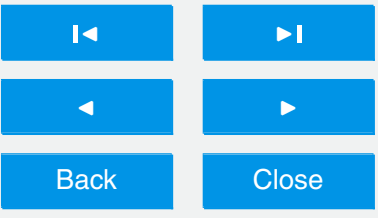

Back

Full Screen / Esc

Printer-friendly Version

Interactive Discussion 
Table 3. Regression equations for the intensity of the aerosol conversion rate and the intensity of the precipitation production rate.

\begin{tabular}{|c|c|c|}
\hline Case & Regression equations with the CCA & Regression equations with the PCA \\
\hline $\mathrm{E}_{1}$ & $R_{\mathrm{a}-\mathrm{conv}}=1.0390 R_{\mathrm{c}-\mathrm{conv}}^{0.9758}, R=0.9954$ & $R_{\mathrm{a}-\mathrm{conv}}=1.3698 R_{\mathrm{c}-\text { conv }}^{0.9725}, R=0.9907$ \\
\hline $\mathrm{E}_{2}$ & $R_{\mathrm{a}-\mathrm{conv}}=0.6755 R_{\mathrm{c}-\mathrm{conv}}^{0.8865}, R=0.9766$ & $24 R_{\mathrm{c}-\mathrm{conv}}^{0.9216}, R=0.9530$ \\
\hline $\mathrm{E}_{3}$ & $R_{\mathrm{a} \text {-conv }}=1.0406 R_{\mathrm{c}-\text { conv }}^{0.9848}, R=0.9971$ & $R_{\mathrm{a}-\mathrm{conv}}=1.5426 R_{\mathrm{c}-\text { conv }}^{0.9933}, R=0.9941$ \\
\hline $\mathrm{E}_{4}$ & $R_{\mathrm{a}-\mathrm{conv}}=0.5511 R_{\mathrm{c}-\mathrm{conv}}^{0.9062}, R=0.9854$ & $R_{\mathrm{a} \text {-conv }}=0.6919 R_{\mathrm{c}-\text { conv }}^{0.8953}, R=0.9840$ \\
\hline$E_{5}$ & $R_{\mathrm{a} \text {-conv }}=0.8348 R_{\mathrm{c}-\mathrm{connv}}^{0.9521}, R=0.9923$ & $R_{\mathrm{a}-\mathrm{conv}}=0.9687 R_{\mathrm{c}-\text { conv }}^{0.9332}, R=0.9867$ \\
\hline $\mathrm{E}_{6}$ & $R_{\mathrm{a}-\mathrm{conv}}=1.2804 R_{\mathrm{c}-\mathrm{conv}}^{0.9956}, R=0.9969$ & $9389 R_{\mathrm{c}-\mathrm{conv}}^{1.0119}, R=0.9948$ \\
\hline $\mathrm{E}_{7}$ & $R_{\mathrm{a} \text {-conv }}=1.3585 R_{\mathrm{c}-\mathrm{conv}}^{1.0061}, R=0.9976$ & $90 R_{\mathrm{c}-\mathrm{conv}}^{1.0397}, R=0.9941$ \\
\hline SM1 & $R_{\mathrm{a}-\mathrm{conv}}=1.2549 R_{\mathrm{c}-\mathrm{conv}}^{1.1083}, R=0.9951$ & $91 R_{\mathrm{c}-\mathrm{Conv}}^{1.1305}, R=0.9910$ \\
\hline SM2 & $R_{\mathrm{a}-\mathrm{conv}}=1.2163 R_{\mathrm{c}-\mathrm{conv}}^{1.1000}, R=0.9951$ & $7 R_{\mathrm{c}-\mathrm{conv}}^{1.1254}, R=0.9901$ \\
\hline SM3 & $R_{\mathrm{a}-\mathrm{conv}}=1.3203 R_{\mathrm{c}-\mathrm{conv}}^{1.1044}, R=0.9981$ & $R_{\mathrm{a}-\mathrm{conv}}=1.4049 R_{\mathrm{c}-\text { conv }}^{1.1360}, R=0.9940$ \\
\hline SM4 & $R_{\mathrm{a}-\mathrm{conv}}=0.3652 R_{\mathrm{c}-\mathrm{conv}}^{0.8854}, R=0.9753$ & $7 R_{\mathrm{c}-\mathrm{conv}}^{0.8691}, R=0.9676$ \\
\hline SM5 & $R_{\mathrm{a} \text {-conv }}=0.6331 R_{\mathrm{c}-\text { conv }}^{1.0392}, R=0.9883$ & $5 R_{\mathrm{c}-\text { conv }}^{1.0437}, R=0.9929$ \\
\hline TM1-M & $R_{\mathrm{a}-\mathrm{conv}}=0.3243 R_{\mathrm{c}-\mathrm{conv}}^{0.8396}, R=0.9777$ & $08 R_{\mathrm{c}-\mathrm{conv}}^{0.8219}, R=0.9668$ \\
\hline TM1-C & $R_{\mathrm{a}-\mathrm{conv}}=0.2021 R_{\mathrm{c}-\mathrm{conv}}^{0.7846}, R=0.9505$ & $R_{\mathrm{a} \text {-conv }}=0.2412 R_{\mathrm{c}-\text { conv }}^{0.7569}, R=0.9463$ \\
\hline TM1-B & $R_{\mathrm{a}-\mathrm{conv}}=0.2540 R_{\mathrm{c}-\mathrm{conv}}^{0.8239}, R=0.9587$ & $R_{\mathrm{a}-\mathrm{conv}}=0.8059 R_{\mathrm{c}-\mathrm{conv}}^{0.8648}, R=0.9535$ \\
\hline TM1-U & $R_{\mathrm{a} \text {-conv }}=0.0733 R_{\mathrm{c}-\text { conv }}^{0.8131}, R=0.8925$ & $R_{\mathrm{a} \text {-conv }}=16.4710 R_{\mathrm{c}-\mathrm{conv}}^{1.1000}, R=0.9457$ \\
\hline
\end{tabular}

CCA: complete coalescence approach; PCA: partial coalescence approach.
Aerosol conversion parameterizations in warm rain formation of cumulus clouds

J. Sun et al.

Title Page

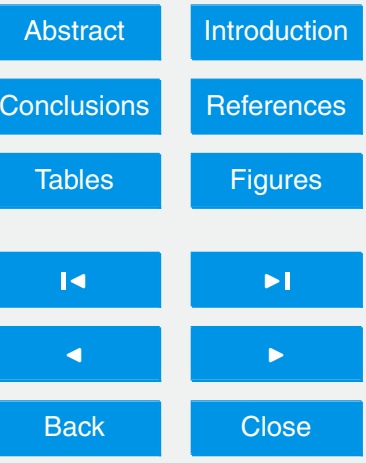

Full Screen / Esc

Printer-friendly Version

Interactive Discussion 
Table 4. Regression equations for autoconversion processes and accretion processes.

\begin{tabular}{|c|c|c|}
\hline Case & $\begin{array}{l}\text { Regression equations for } \\
\text { autoconversion processes }\end{array}$ & $\begin{array}{l}\text { Regression equations for } \\
\text { accretion processes }\end{array}$ \\
\hline$E_{1}$ & $R_{\text {a-auto }}=15.4870 R_{\text {C-auto }}^{1.093}, R=0.9768$ & $R_{\mathrm{a} \text {-accre }}=1.1027 R_{\mathrm{c}-\mathrm{accre}}^{0.9888}, R=0.9996$ \\
\hline $\mathrm{E}_{2}$ & $R_{\text {a-auto }}=25.368 R_{\text {c-auto }}^{1.1268}, R=0.8527$ & $R_{\text {a-accre }}=0.9242 R_{\mathrm{c}-\mathrm{accre}}^{0.960}, R=0.9991$ \\
\hline$E_{3}$ & $R_{\text {a-auto }}=7.8092 R_{\text {c-auto }}^{1.0553}, R=0.9780$ & $R_{\mathrm{a}-\mathrm{accre}}=1.1625 R_{\mathrm{c}-\mathrm{accre}}^{0.9939}, R=0.9997$ \\
\hline $\mathrm{E}_{4}$ & $R_{\text {a-auto }}=1.8635 R_{\text {c-auto }}^{0.9650}, R=0.9817$ & $R_{\mathrm{a}-\mathrm{accre}}=0.9137 R_{\mathrm{c}-\mathrm{accre}}^{0.900}, R=0.9997$ \\
\hline$E_{5}$ & $R_{\text {a-auto }}=7.8254 R_{\text {c-auto }}^{1.0368}, R=0.9775$ & $R_{\mathrm{a} \text {-accre }}=1.0281 R_{\mathrm{c}-\mathrm{accre}}^{0.9893}, R=0.9997$ \\
\hline $\mathrm{E}_{6}$ & $R_{\text {a-auto }}=15.4700 R_{\text {c-auto }}^{1.1209}, R=0.9806$ & $R_{\mathrm{a} \text {-accre }}=1.2830 R_{\mathrm{c}-\text { accre }}^{0.997}, R=0.9997$ \\
\hline$E_{7}$ & $R_{\text {a-auto }}=8.0669 R_{\text {c-auto }}^{1.0974}, R=0.9794$ & $R_{\mathrm{a}-\mathrm{accre}}=1.3856 R_{\mathrm{c}-\mathrm{accre}}^{0.994}, R=0.9996$ \\
\hline SM1 & $R_{\text {a-auto }}=1.0577 R_{\text {c-auto }}^{1.1350}, R=0.9682$ & $R_{\mathrm{a}-\mathrm{accre}}=0.8582 R_{\mathrm{c}-\mathrm{accre}}^{1.0245}, R=0.9970$ \\
\hline SM2 & $R_{\text {a-auto }}=1.6989 R_{\text {c-auto }}^{1.1473}, R=0.9769$ & $R_{\mathrm{a} \text {-accre }}=0.8504 R_{\mathrm{c} \text {-accre }}^{1.0268}, R=0.9974$ \\
\hline SM3 & $R_{\text {a-auto }}=1.4126 R_{\text {c-auto }}^{1.1300}, R=0.9967$ & $R_{\mathrm{a}-\mathrm{accre}}=0.7777 R_{\mathrm{c}-\mathrm{accre}}^{1.0055}, R=0.9986$ \\
\hline SM4 & $R_{\text {a-auto }}=0.4940 R_{\text {c-auto }}^{0.911}, R=0.9526$ & $R_{\mathrm{a}-\mathrm{accre}}=0.8161 R_{\mathrm{c}-\mathrm{accre}}^{0.957}, R=0.9995$ \\
\hline SM5 & $R_{\text {a-auto }}=0.9413 R_{\text {c-auto }}^{1.0050}, R=0.9769$ & $R_{\mathrm{a}-\mathrm{accre}}=0.6694 R_{\mathrm{c}-\mathrm{accre}}^{1.008}, R=0.9975$ \\
\hline TM1-M & $0 R_{\mathrm{c}-\text { auto }}^{0.8363}, R=0.9420$ & $4 R_{\mathrm{c}-\mathrm{accre}}^{0.9947}, R=0.9997$ \\
\hline TM1-C & $R_{\text {a-auto }}=1.6428 R_{\text {c-auto }}^{0.8648}, R=0.9598$ & $R_{\mathrm{a}-\mathrm{accre}}=1.0879 R_{\mathrm{c}-\mathrm{accre}}^{0.9804}, R=0.9952$ \\
\hline TM1-B & $R_{\text {a-auto }}=53.4529 R_{\text {c-auto }}^{1.0408}, R=0.9733$ & $R_{\mathrm{a}-\mathrm{accre}}=1.0661 R_{\mathrm{c}-\mathrm{accre}}^{0.9923}, R=0.9997$ \\
\hline TM1-U & $R_{\text {a-auto }}=232.8746 R_{\text {c-auto }}^{1.1752}, R=0.9786$ & $R_{\mathrm{a}-\mathrm{accre}}=0.7362 R_{\mathrm{c}-\mathrm{accre}}^{0.9855}, R=0.9989$ \\
\hline
\end{tabular}

Aerosol conversion parameterizations in warm rain formation of cumulus clouds

J. Sun et al.

Title Page

Abstract

Introduction

Conclusions

References

Tables

Figures

14

4

Back

Close

Full Screen / Esc

Printer-friendly Version

Interactive Discussion 


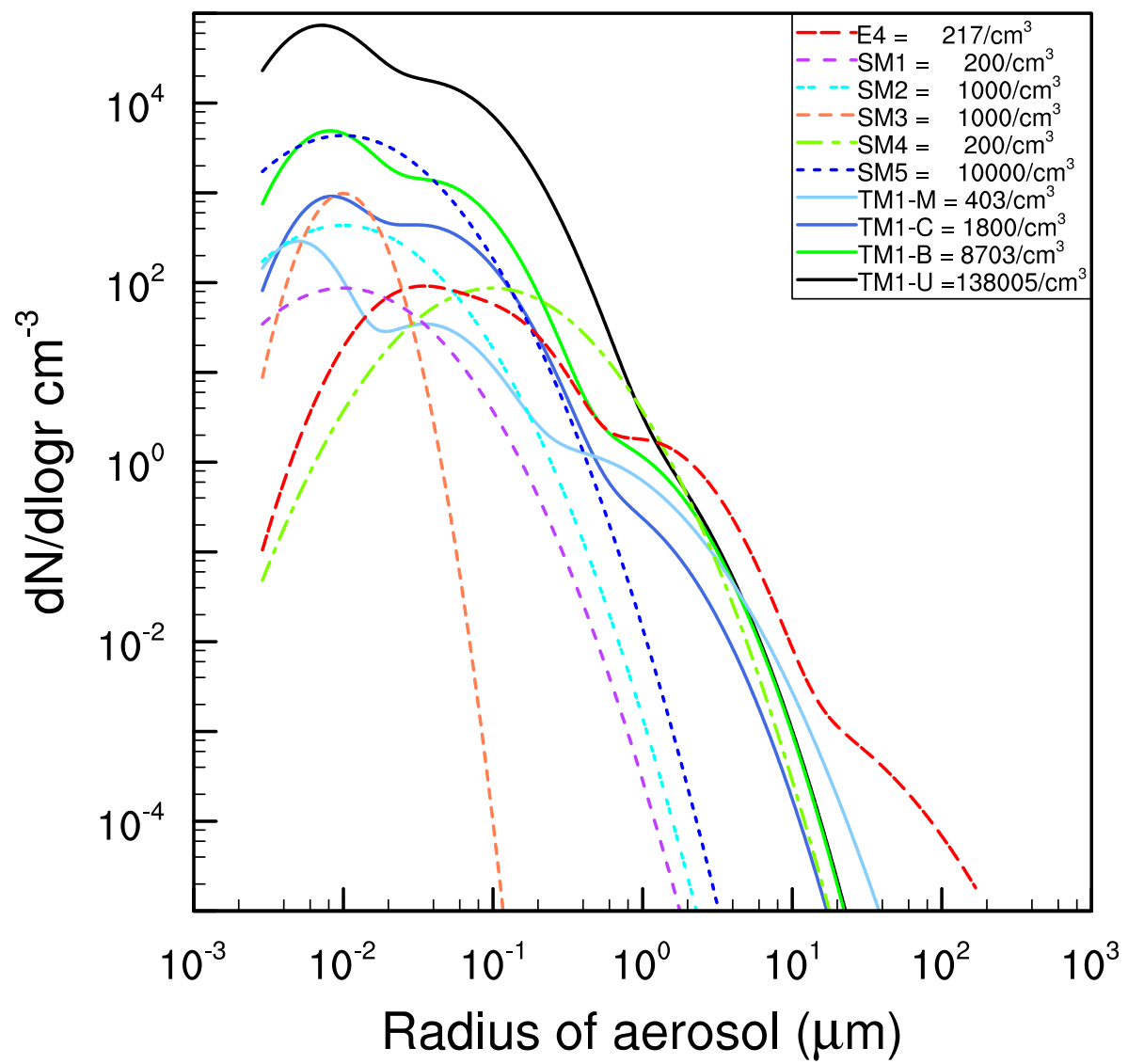

Fig. 1. Different aerosol distributions from Whitby (1978), Nenes and Seinfeld (2003) and Sun et al. (2012a) for numerical experiments.
ACPD

13, 25481-25536, 2013

Aerosol conversion parameterizations in warm rain formation of cumulus clouds

J. Sun et al.

\section{Title Page}

\section{Abstract}

Conclusions

Tables

14

Back

\section{Full Screen / Esc}

Printer-friendly Version

Interactive Discussion 

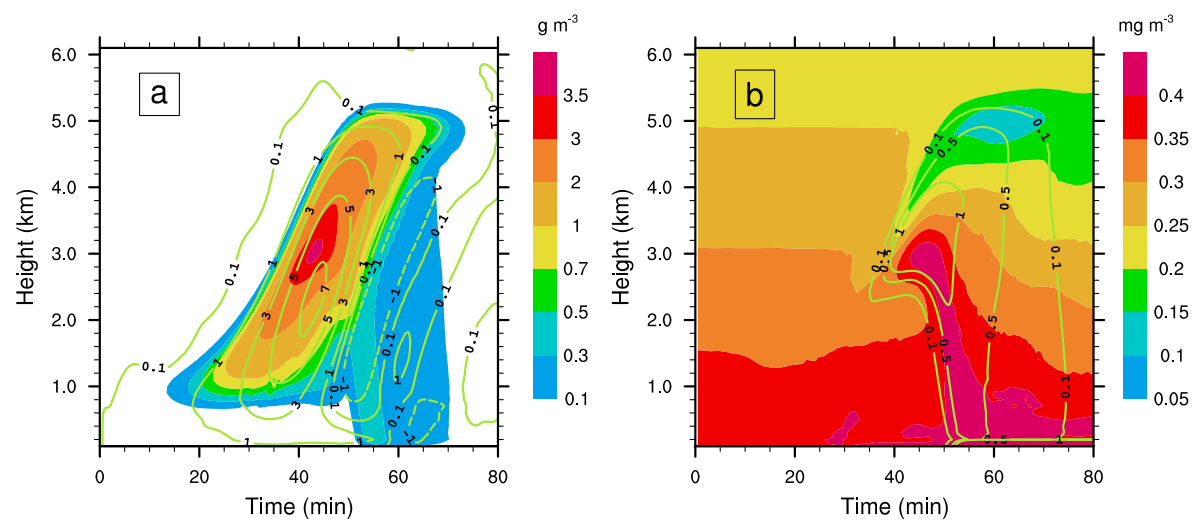

\section{ACPD}

13, 25481-25536, 2013

Aerosol conversion parameterizations in warm rain formation of cumulus clouds

J. Sun et al.

Title Page

Abstract

Conclusions

Tables

14

Back

Fig. 2. Temporal and spatial evolution of the simulated cumulus cloud for the case $E_{1}$. (a) Vertical velocities $\left(\mathrm{m} \mathrm{s}^{-1}\right)$ (solid and dashed lines) and liquid water content (in $\mathrm{g} \mathrm{m}^{-3}$ ) (shaded area); (b) rain water content (in $\mathrm{g} \mathrm{m}^{-3}$ ) (solid lines) and ammonium sulfate mass content $\left(\mathrm{mg} \mathrm{m}^{-3}\right.$ ) (shaded area).

\section{Full Screen / Esc}

Printer-friendly Version 

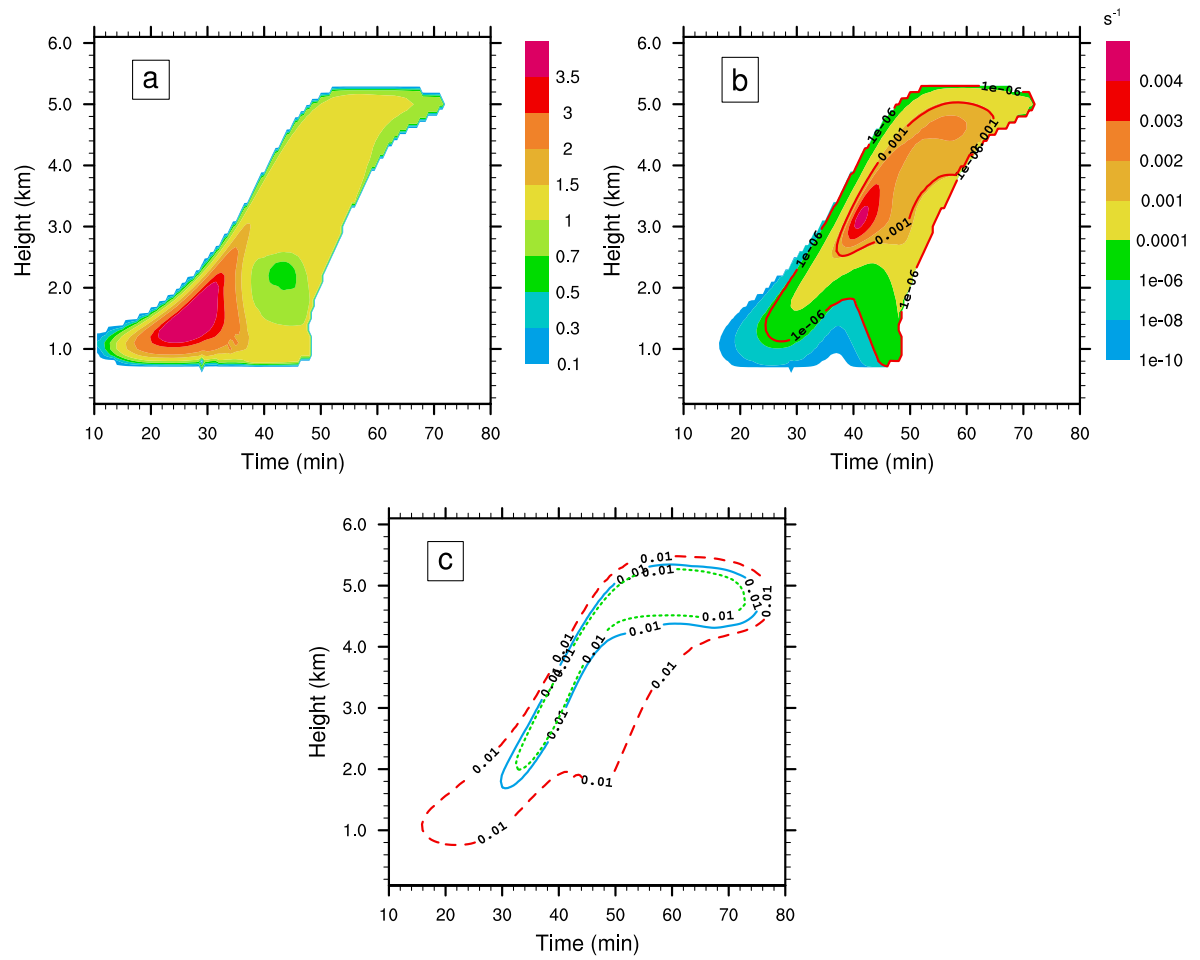

Fig. 3. Spatial and temporal evolution of ammonium sulfate and cloud water conversions with the complete coalescence approach for the case $\mathrm{E}_{1}$. (a) Ratio of $R_{\mathrm{a} \text {-conv }}$ to $R_{\mathrm{c} \text {-conv }}$ (shaded area); (b) $R_{\text {a-conv }}\left(\mathrm{s}^{-1}\right)$ (shaded area) and $R_{\text {c-conv }}\left(\mathrm{s}^{-1}\right)$ (solid lines); (c) water drop concentrations in different size categories: cloud droplets with diameters $>50.0 \mu \mathrm{m}\left(\mathrm{cm}^{-3}\right)$ (dashed lines), drizzle drops with diameters $>80.0 \mu \mathrm{m}\left(\mathrm{cm}^{-3}\right)$ (solid lines), and drizzle drops with diameters $>100.0 \mu \mathrm{m}\left(\mathrm{cm}^{-3}\right)$ (dotted lines).
ACPD

13, 25481-25536, 2013

Aerosol conversion parameterizations in warm rain formation of cumulus clouds

J. Sun et al.

\section{Title Page}

Abstract

Conclusions

Tables

14

Back
Introduction

References

Figures

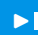

$>$

Close

\section{Full Screen / Esc}

Printer-friendly Version 

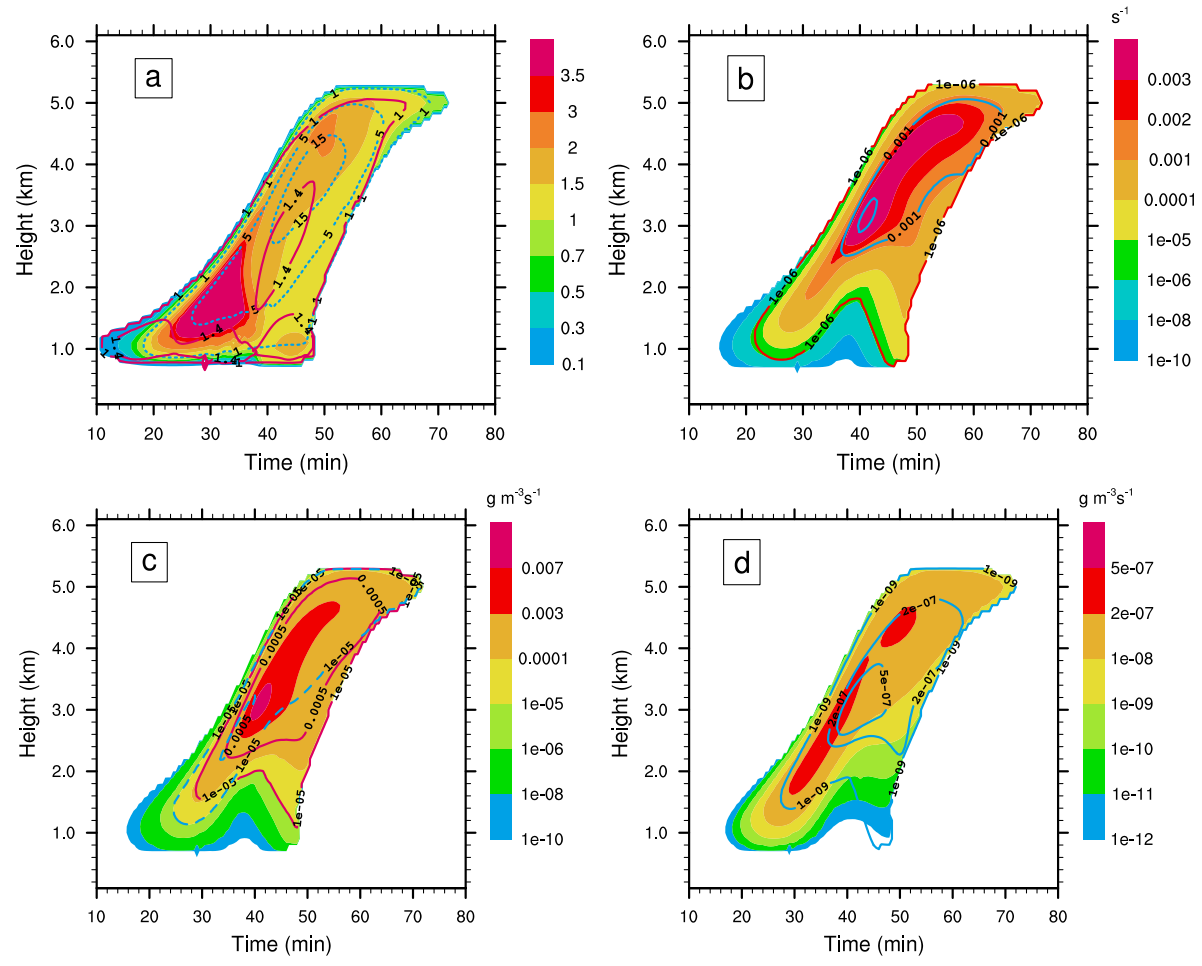

Fig. 4. Spatial and temporal evolution of ammonium sulfate and cloud water conversions with the partial coalescence approach for the case $\mathrm{E}_{1}$. (a) Ratio of $R_{\mathrm{a} \text {-conv }}$ to $R_{\text {c-conv }}$ (shaded area), ratio of $R_{\text {a-auto }}$ to $R_{\text {c-auto }}$ (dotted lines), and ratio of $R_{\text {a-accre }}$ to $R_{\text {c-accre }}$ (dashed lines); (b) $R_{\mathrm{a}-\mathrm{conv}}\left(\mathrm{s}^{-1}\right)$ (shaded area) and $R_{\mathrm{c}-\mathrm{conv}}\left(\mathrm{s}^{-1}\right)$ (solid lines). (c) Precipitation production rates $\left(\mathrm{g} \mathrm{m}^{-3} \mathrm{~s}^{-1}\right)$ (shaded area), autoconversion rates $\left(\mathrm{g} \mathrm{m}^{-3} \mathrm{~s}^{-1}\right)$ (dashed lines) and accretion rates $\left(\mathrm{g} \mathrm{m}^{-3} \mathrm{~s}^{-1}\right)$ (solid lines) of the cloud liquid water content; (d) autoconversion rates $\left(\mathrm{g} \mathrm{m}^{-3} \mathrm{~s}^{-1}\right)$ (shaded area) and accretion rates $\left(\mathrm{g} \mathrm{m}^{-3} \mathrm{~s}^{-1}\right.$ ) (solid lines) of the ammonium sulfate mass concentration.

\section{ACPD}

13, 25481-25536, 2013

Aerosol conversion parameterizations in warm rain formation of cumulus clouds

J. Sun et al.

\section{Title Page}

\section{Abstract}

Conclusions

Tables

14

Back

\section{Introduction}

References

Figures

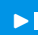

\section{Close}

\section{Full Screen / Esc}

Printer-friendly Version 


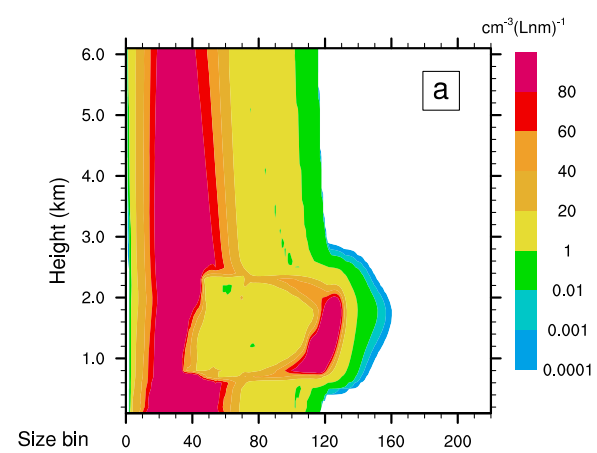

Diameter $(\mu \mathrm{m}) \quad 0.154 \quad 1.553 \quad 15.65 \quad 157.75 \quad 1590.1$

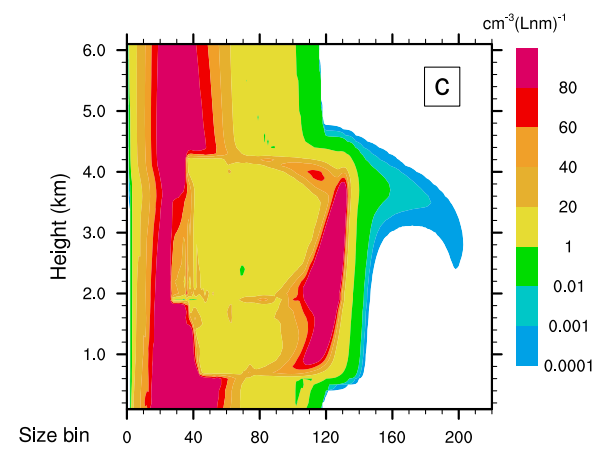

Diameter $(\mu \mathrm{m}) \quad 0.154 \quad 1.553 \quad 15.65 \quad 157.75 \quad 1590.1$

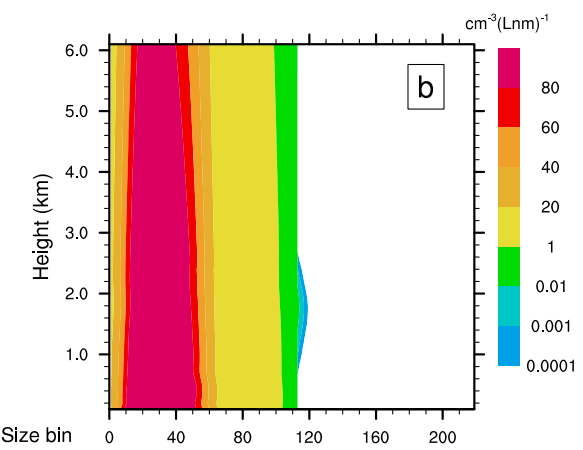

Diameter $(\mu \mathrm{m}) \quad 0.154 \quad 1.553 \quad 15.65 \quad 157.75 \quad 1590.1$

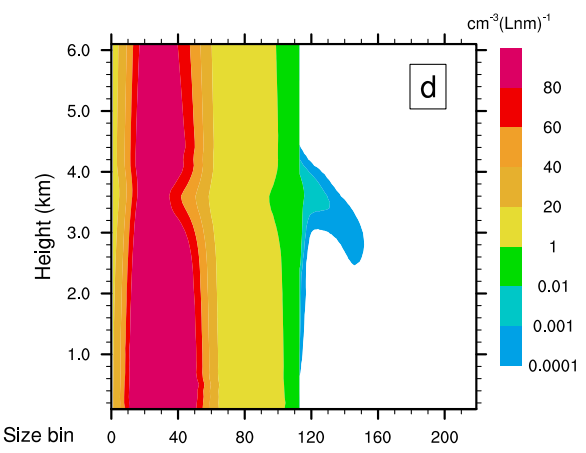

Diameter $(\mu \mathrm{m}) \quad 0.154 \quad 1.553 \quad 15.65 \quad 157.75 \quad 1590.1$

\section{ACPD}

13, 25481-25536, 2013

Aerosol conversion parameterizations in warm rain formation of cumulus clouds

J. Sun et al.

\section{Title Page}

\section{Abstract}

Introduction

Conclusions

References

Tables

Figures

14

DI

4

Back

\section{Close}

Fig. 5. Number distributions of ammonium sulfate particles and of water droplets as a function of height $f\left(\ln m_{\text {water }}, \ln m_{\text {aerosol }}, z\right)$ (numbercm $\left.{ }^{-3}\left(\operatorname{ln~m}_{\text {water }} / \operatorname{ln~m}_{\text {aerosol }}\right)^{-1}\right)$ at $30 \mathrm{~min}(\mathbf{a}, \mathbf{b})$ and at $42.5 \mathrm{~min}(\mathbf{c}, \mathbf{d})$ for the case $\left.\mathrm{E}_{1}: \mathbf{( a ,} \mathbf{c}\right)$. With respect to $\ln m_{\text {water }},(\mathbf{b}, \mathbf{d})$. With respect to $\ln m_{\text {aerosol }}$.

Full Screen / Esc

Printer-friendly Version

Interactive Discussion 

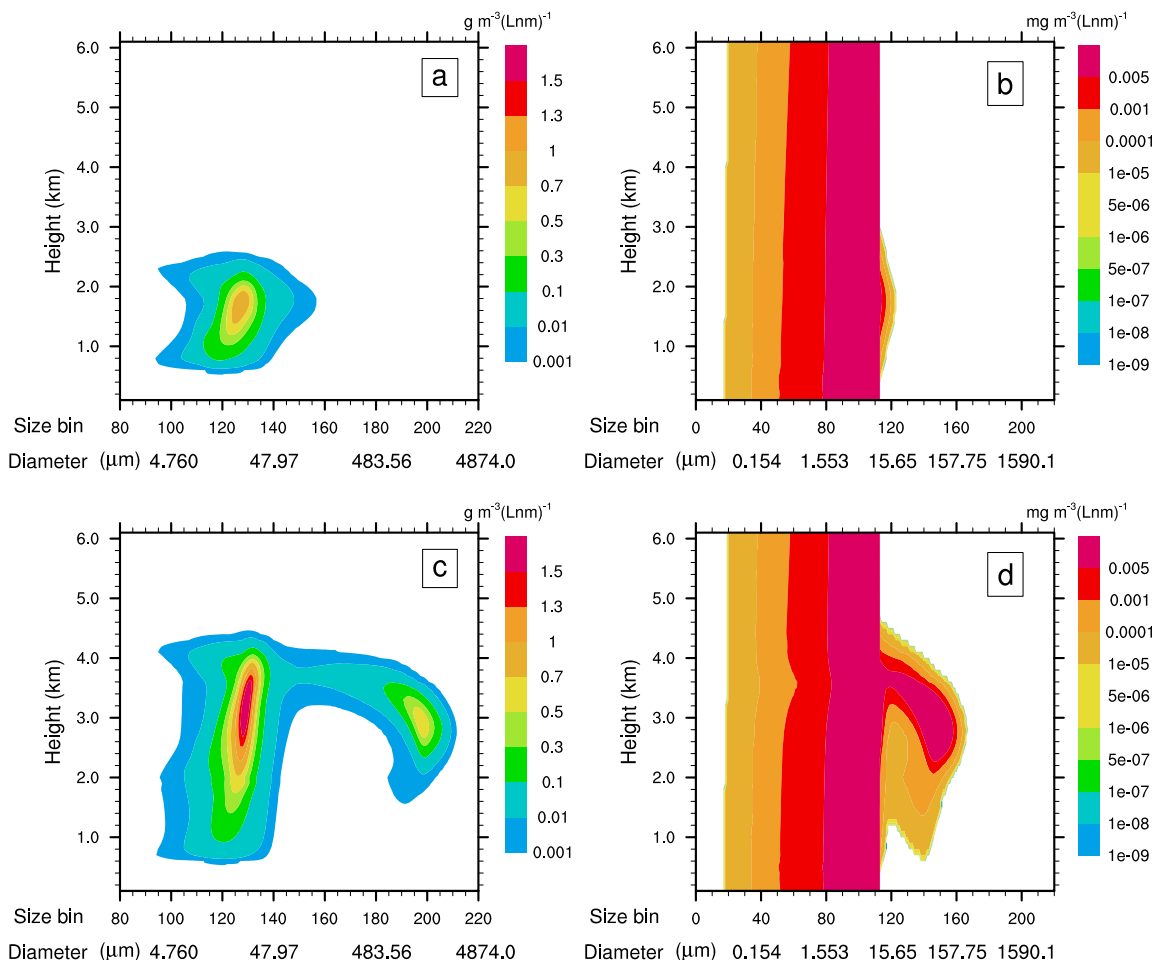

Diameter $(\mu \mathrm{m}) \quad 0.154 \quad 1.553 \quad 15.65 \quad 157.75 \quad 1590.1$

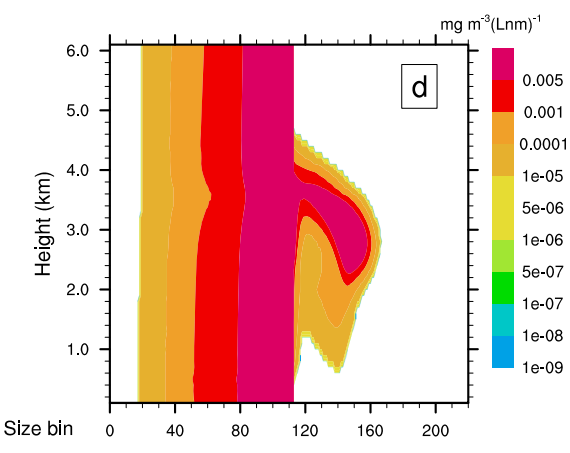

Diameter $(\mu \mathrm{m}) \quad 0.154 \quad 1.553 \quad 15.65 \quad 157.75 \quad 1590.1$

\section{ACPD}

13, 25481-25536, 2013

Aerosol conversion parameterizations in warm rain formation of cumulus clouds

J. Sun et al.

\section{Title Page}

\section{Abstract}

Introduction

Conclusions

References

Tables

Figures

14

DI

Back

Close

Fig. 6. Mass distributions of water droplets and of ammonium sulfate particles as a function of height $g\left(\ln m_{\text {water }}, z\right)\left(\mathrm{g} \mathrm{m}^{-3}\left(\operatorname{lnm}_{\text {water }}\right)^{-1}\right)$ and $g\left(\ln m_{\text {aerosol }}, z\right)\left(\mathrm{mg} \mathrm{m}^{-3}\left(\operatorname{lnm}_{\text {aerosol }}\right)^{-1}\right)$, respectively, at $30 \mathrm{~min}(\mathbf{a}, \mathbf{b})$ and at $42.5 \mathrm{~min}(\mathbf{c}, \mathbf{d})$ for the case $\mathrm{E}_{1}$.

\section{Full Screen / Esc}

Printer-friendly Version

Interactive Discussion 

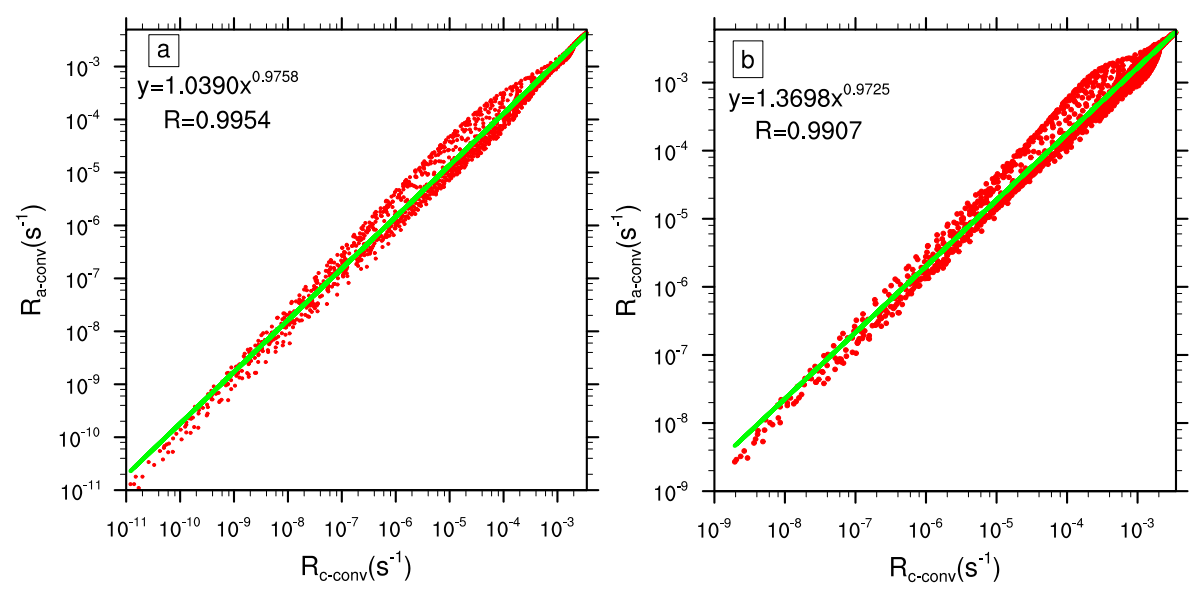

\section{ACPD}

13, 25481-25536, 2013

Aerosol conversion parameterizations in warm rain formation of cumulus clouds

J. Sun et al.
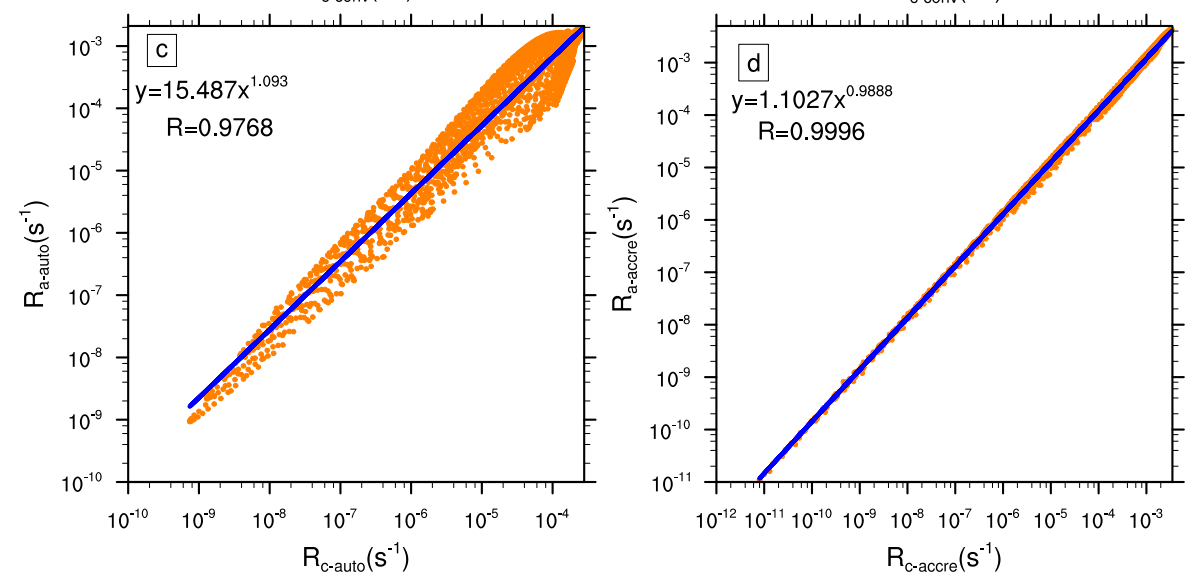

Title Page

Abstract

Conclusions

Tables

14

4

Back

\section{Full Screen / Esc}

Printer-friendly Version
Fig. 7. Illustrations of linear regressions for the case $\mathrm{E}_{1}$. (a) The linear regression of $\ln \left(R_{\mathrm{c}-\mathrm{conv}}\right)$ and $\ln \left(R_{\mathrm{a}-\mathrm{conv}}\right)$ with the complete coalescence approach. (b) The linear regression of $\ln \left(R_{\mathrm{c}-\text { conv }}\right)$ and $\ln \left(R_{\text {a-conv }}\right)$ with the partial coalescence approach. (c) The linear regression of $\ln \left(R_{\text {c-auto }}\right)$ and $\ln \left(R_{\text {a-auto }}\right)$. (d) The linear regression of $\ln \left(R_{\text {c-accre }}\right)$ and $\ln \left(R_{\text {a-accre }}\right)$. 

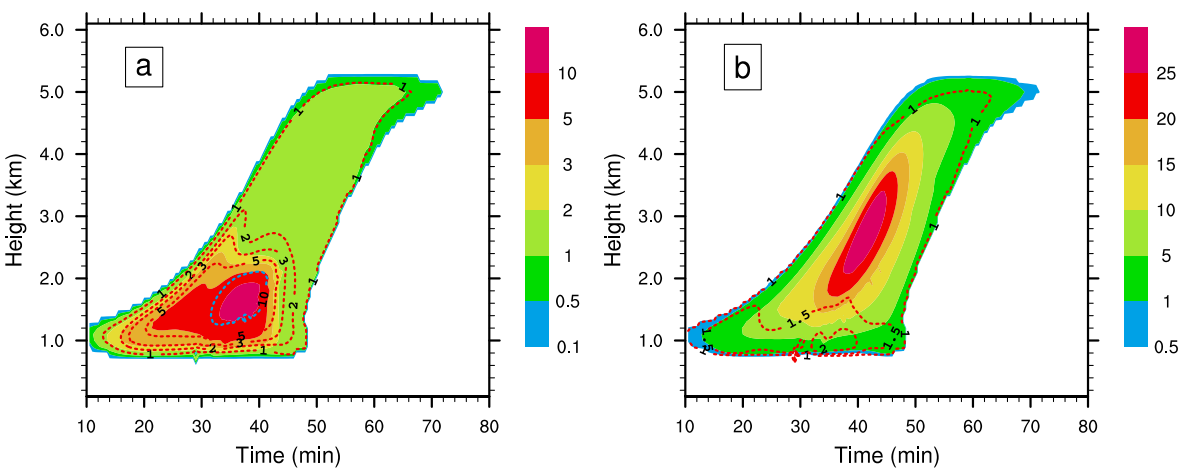

\section{ACPD}

13, 25481-25536, 2013

\section{Aerosol conversion parameterizations in warm rain formation of cumulus clouds}

J. Sun et al.

\section{Title Page}

\section{Abstract}

Conclusions

Tables

14

4

Back

4

Fig. 8. Spatial and temporal evolution of ammonium sulfate and cloud water conversions for the case $\mathrm{E}_{2}$. (a) Ratio of $R_{\mathrm{a}-\mathrm{conv}}$ to $R_{\mathrm{c} \text {-conv }}$ with the complete coalescence approach (shaded area), and ratio of $R_{\text {a-conv }}$ to $R_{\text {c-conv }}$ with the partial coalescence approach (dotted lines); (b) ratio of $R_{\text {a-auto }}$ to $R_{\text {c-auto }}$ (shaded area) and ratio of $R_{\text {a-accre }}$ to $R_{\text {c-accre }}$ (dotted lines).

\section{Full Screen / Esc}

Printer-friendly Version 

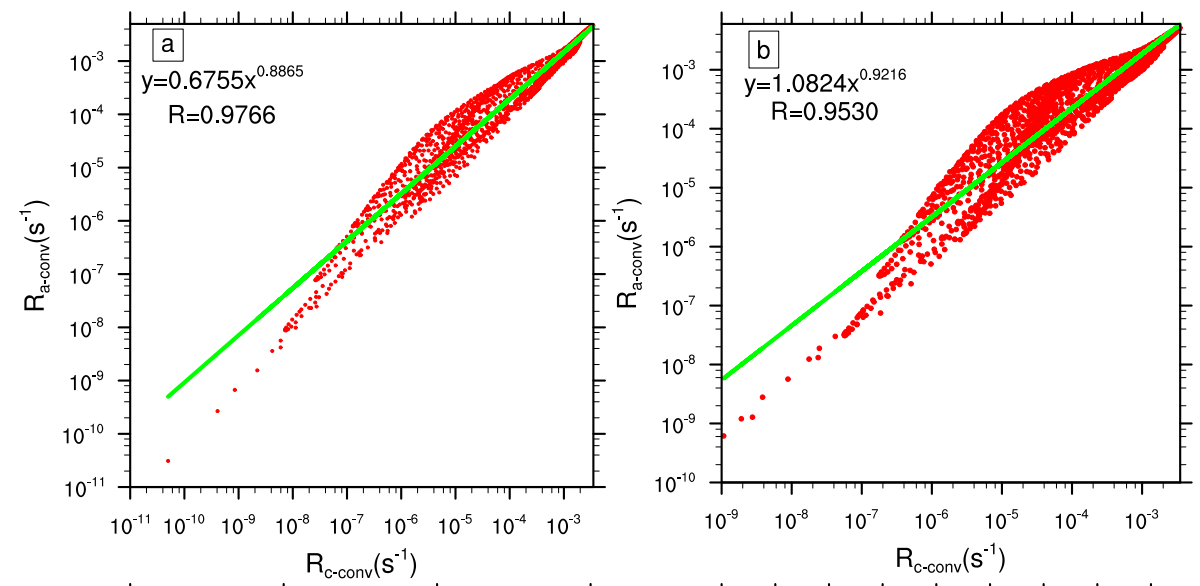

\section{ACPD}

13, 25481-25536, 2013

Aerosol conversion parameterizations in warm rain formation of cumulus clouds

J. Sun et al.

\section{Title Page}
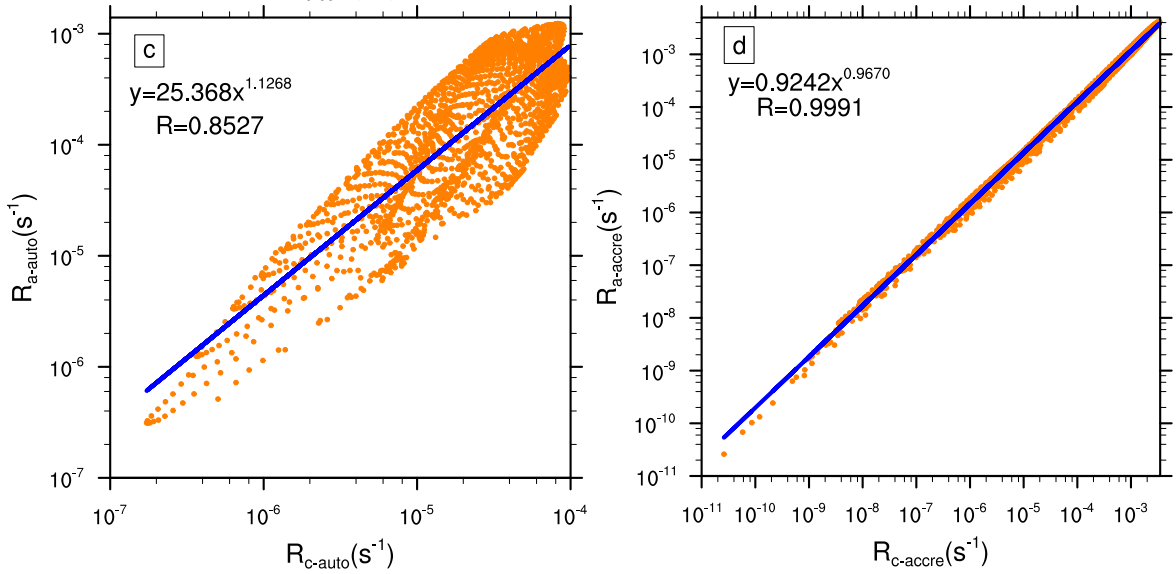

Abstract

Introduction

Conclusions

References

Tables

Figures

14

$\Delta$

Back

Close

Full Screen / Esc

Printer-friendly Version

Interactive Discussion 

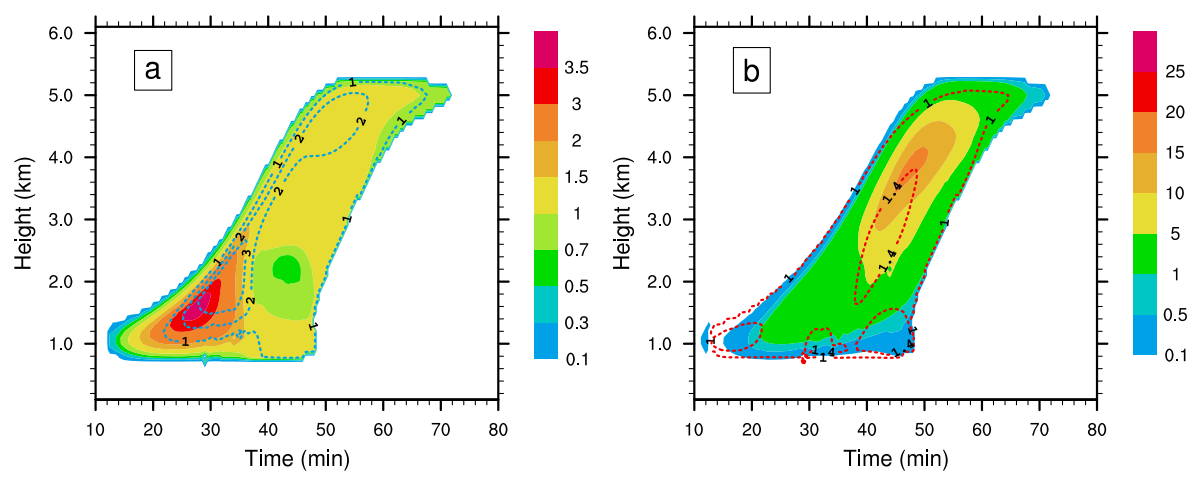

Fig. 10. The meaning of these plots is the same as Fig. 8 but for the case $E_{3}$.

\section{ACPD}

13, 25481-25536, 2013

Aerosol conversion parameterizations in warm rain formation of cumulus clouds

J. Sun et al.

\section{Title Page}

Abstract

Conclusions

Tables

14

4

Back

Full Screen / Esc

Printer-friendly Version

Interactive Discussion 

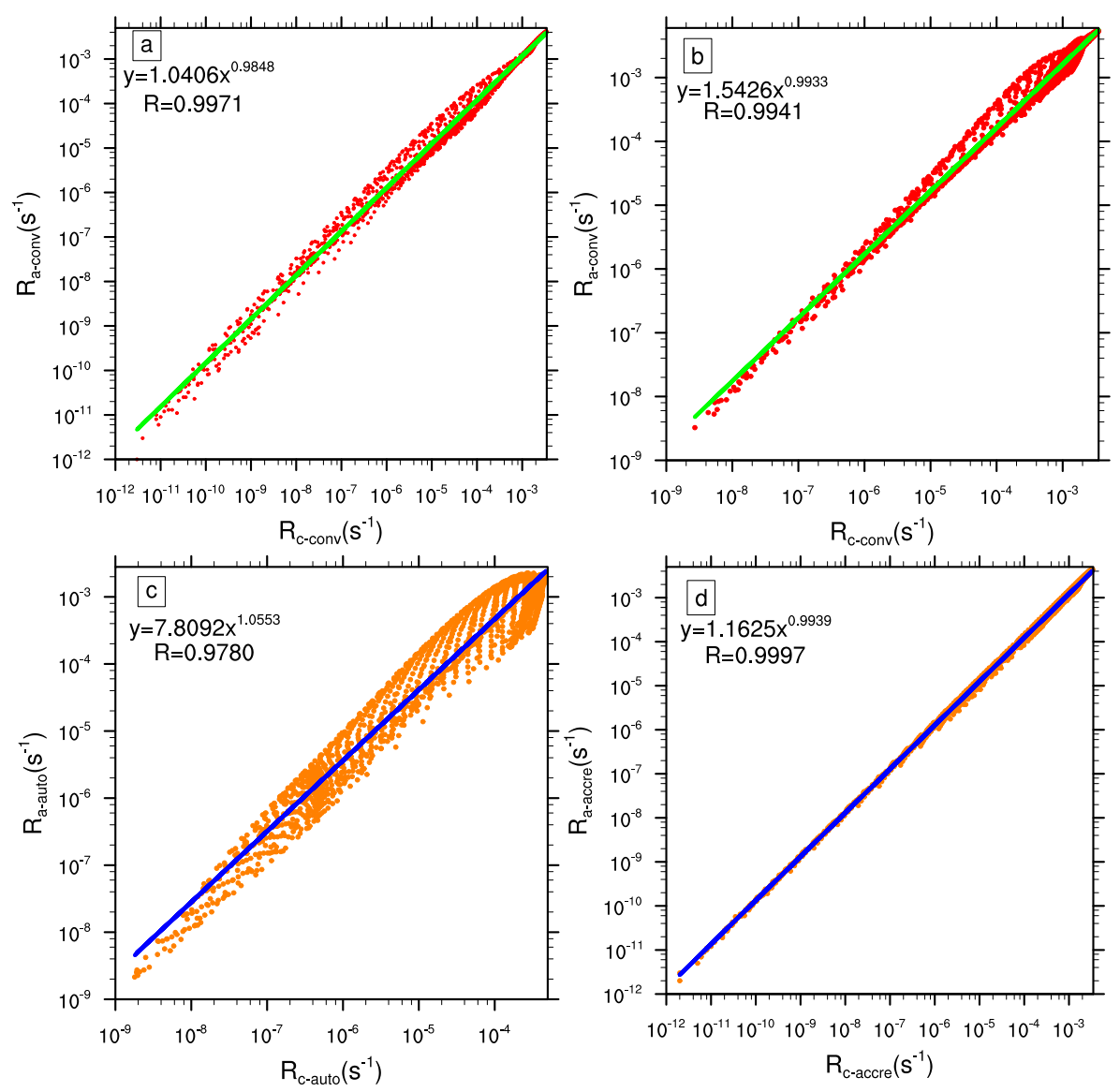

Fig. 11. The meaning of these plots is the same as Fig. 7 but for the case $E_{3}$.

\section{ACPD}

13, 25481-25536, 2013

Aerosol conversion parameterizations in warm rain formation of cumulus clouds

J. Sun et al.

\section{Title Page}

Abstract

Conclusions

Tables

14

4

Back

\section{Full Screen / Esc}

Printer-friendly Version 

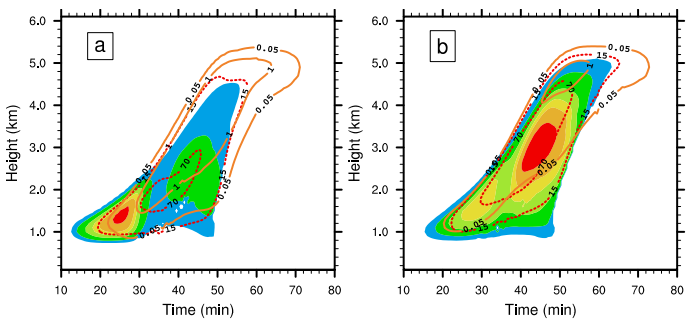

\section{ACPD}

13, 25481-25536, 2013
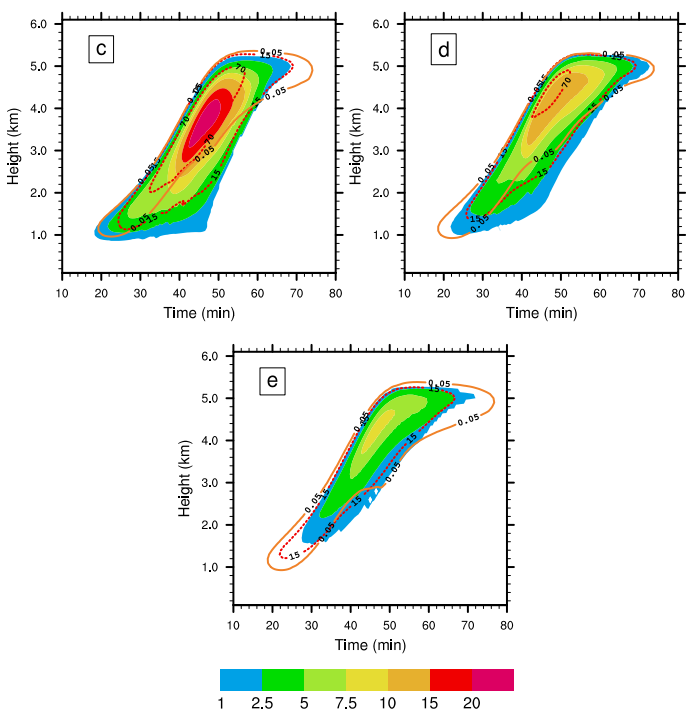

Fig. 12. Spatial and temporal evolution of large cloud droplet concentrations and of ratios of $R_{\text {a-auto }}$ to $R_{\text {c-auto }}$ in different concentrations of ammonium sulfate particles for the cases of $\mathrm{E}_{4}$ (a), $\mathrm{E}_{5}$ (b), $\mathrm{E}_{1}$ (c), $\mathrm{E}_{6}$ (d) and $\mathrm{E}_{7}$ (e). Ratios of $R_{\text {a-auto }}$ to $R_{\text {c-auto }}$ (shaded area), cloud droplets with diameters $>25.0 \mu \mathrm{m}\left(\mathrm{cm}^{-3}\right)$ (dotted lines) and cloud droplets with diameters $>50.0 \mu \mathrm{m}$ $\left(\mathrm{cm}^{-3}\right)$ (solid lines).

Aerosol conversion parameterizations in warm rain formation of cumulus clouds

J. Sun et al.

Title Page

\section{Abstract}

Conclusions

Tables

14

Back

\section{Full Screen / Esc}

Printer-friendly Version 

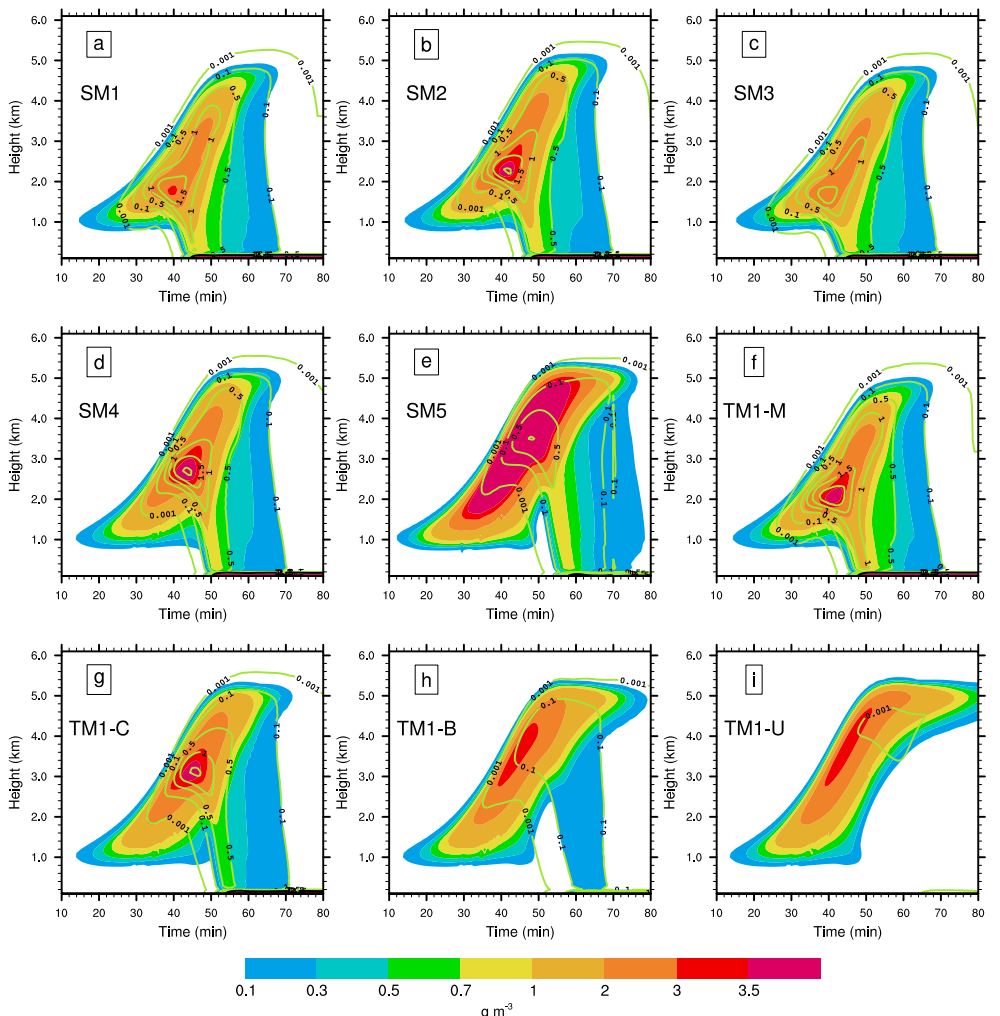

Fig. 13. Temporal and spatial evolution of liquid water content (in $\mathrm{gm}^{-3}$ ) (shaded area) and Rain water content (in $\mathrm{g} \mathrm{m}^{-3}$ ) (solid lines) with different initial aerosol size distributions. (a) For the case SM1. (b) For the case SM2. (c) For the case SM3. (d) For the case SM4. (e) For the case SM5. (f) For the case TM1-M. (g) For the case TM1-C. (h) For the case TM1-B. (i) For the case TM1-U.

\section{ACPD}

13, 25481-25536, 2013

Aerosol conversion parameterizations in warm rain formation of cumulus clouds

J. Sun et al.

Title Page
Abstract

Conclusions

Tables

14

4

Back
Introduction

References

Figures

DI

$>$

Close

\section{Full Screen / Esc}

Printer-friendly Version

Interactive Discussion 

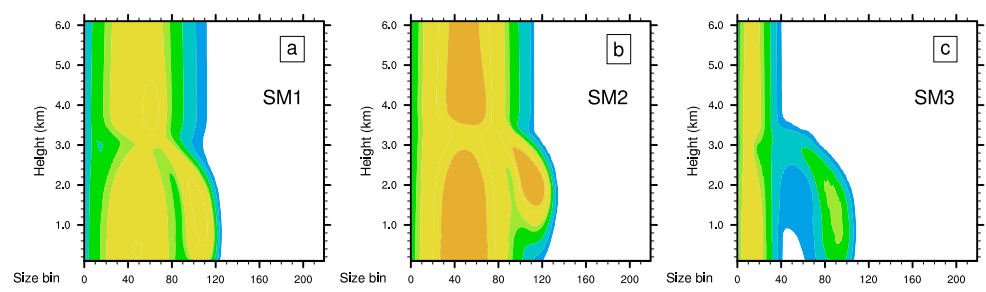

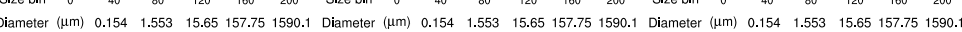
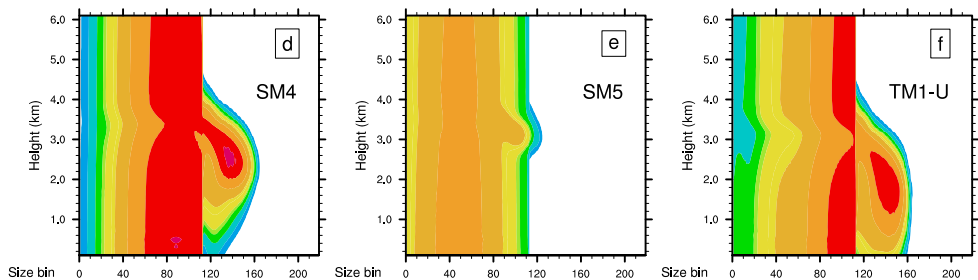

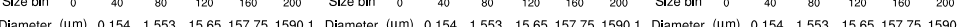
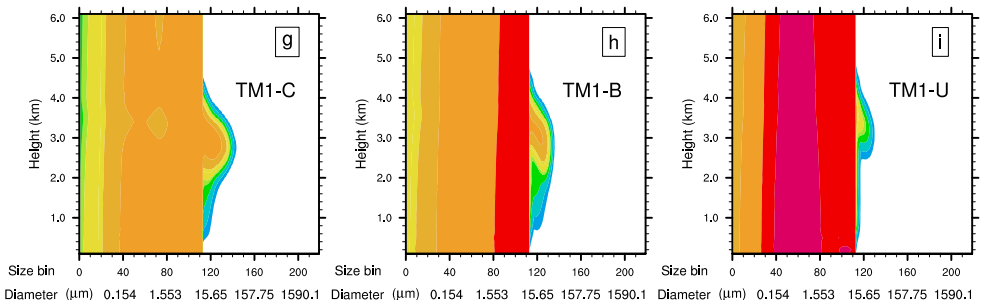

$$
\begin{array}{rrrrr}
1 \mathrm{e}-09 & 1 \mathrm{e}-08 & 1 \mathrm{e}-07 & 5 \mathrm{e}-07 & \begin{array}{r}
1 \mathrm{e}-06 \\
\mathrm{mg} \mathrm{m}^{-3}\left(\mathrm{Lnm}^{-1}\right.
\end{array}
\end{array}
$$

Fig. 14. Mass distributions of ammonium sulfate particles as a function of height $g\left(\ln m_{\text {aerosol }}, z\right)$ $\left(\mathrm{mg} \mathrm{m}^{-3}\left(\mathrm{In} \mathrm{m}_{\text {aerosol }}\right)^{-1}\right)$ at $42.5 \mathrm{~min}$. (a) For the case SM1. (b) For the case SM2. (c) For the case SM3. (d) For the case SM4. (e) For the case SM5. (f) For the case TM1-M. (g) For the case TM1-C. (h) For the case TM1-B. (i) For the case TM1-U.
ACPD

13, 25481-25536, 2013

Aerosol conversion parameterizations in warm rain formation of cumulus clouds

J. Sun et al.

\section{Title Page}

\section{Abstract}

Conclusions

Tables

14

Back
Introduction

References

Figures

$>$ I

Close

\section{Full Screen / Esc}

Printer-friendly Version

Interactive Discussion 

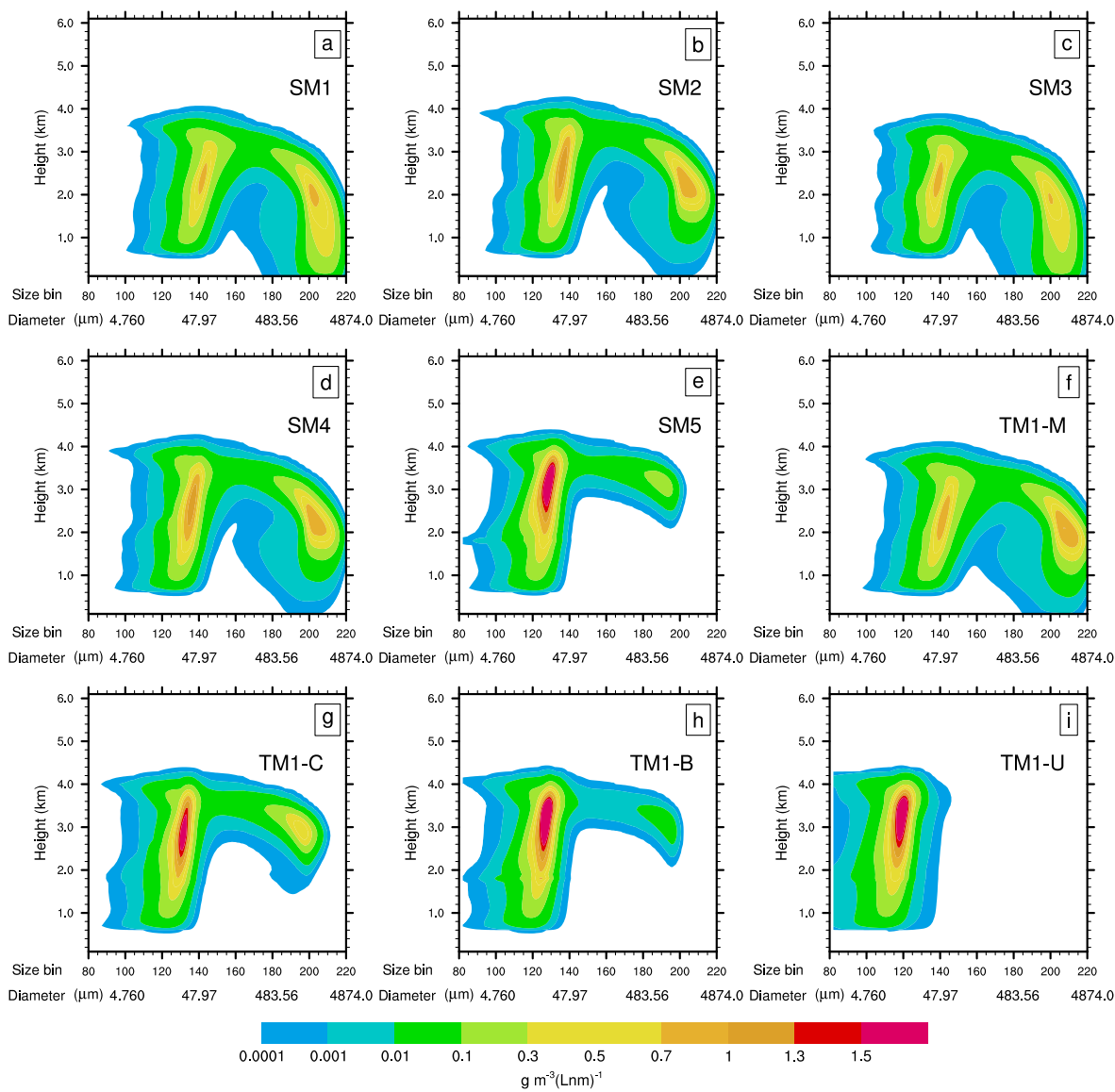

\section{ACPD}

13, 25481-25536, 2013

Aerosol conversion parameterizations in warm rain formation of cumulus clouds

J. Sun et al.

Title Page

Abstract

Conclusions

Tables

14

Back

Full Screen / Esc

Printer-friendly Version

Interactive Discussion

Fig. 15. Mass distributions of water drops as a function of height $g\left(\ln m_{\text {water }}, z\right)$ $\left(\mathrm{g} \mathrm{m}^{-3}\left(\mathrm{In} \mathrm{m}_{\text {water }}\right)^{-1}\right)$ at $42.5 \mathrm{~min}$. (a) For the case SM1. (b) For the case SM2. (c) For the case SM3. (d) For the case SM4. (e) For the case SM5. (f) For the case TM1-M. (g) For the case TM1-C. (h) For the case TM1-B. (i) For the case TM1-U. 

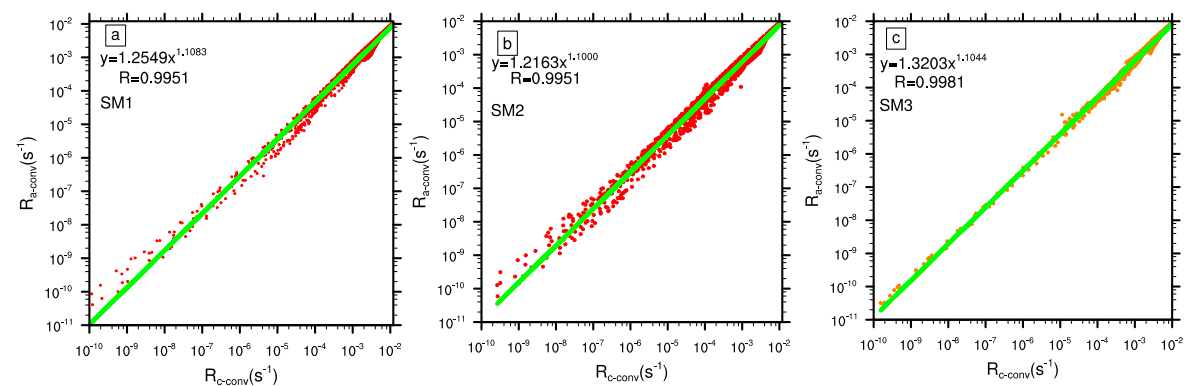

\section{ACPD}

13, 25481-25536, 2013
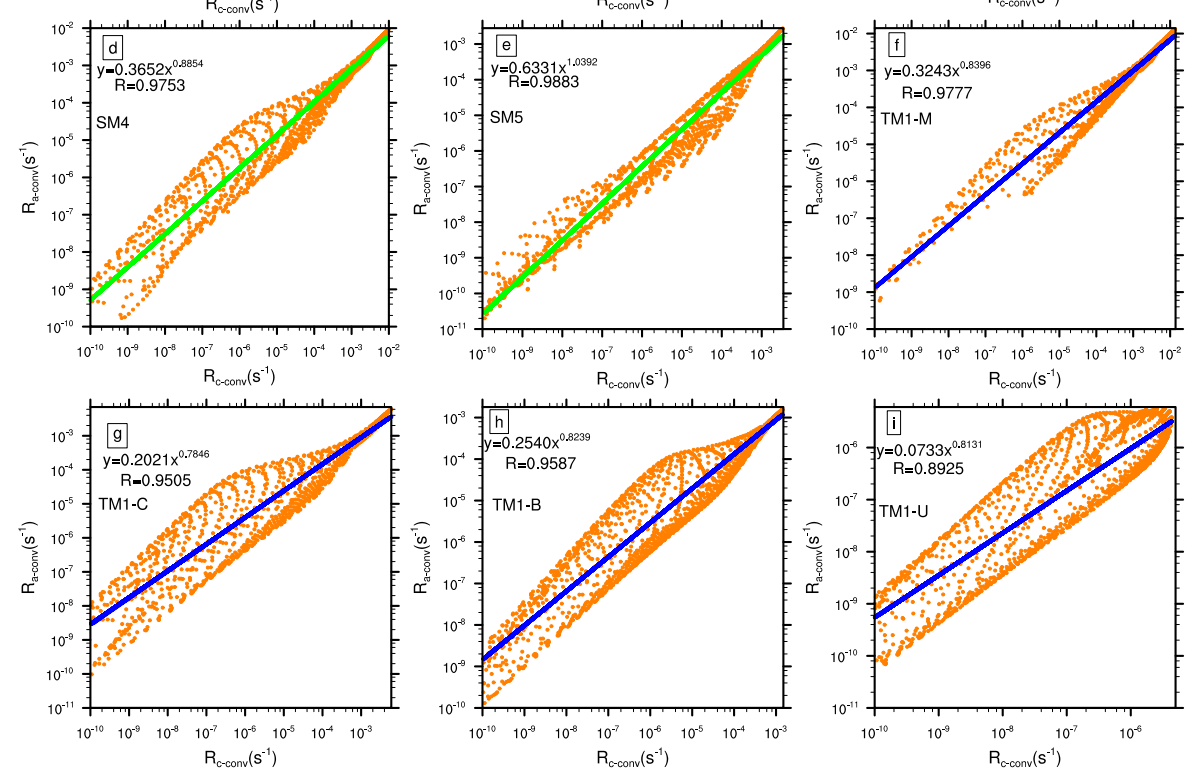

\section{Aerosol conversion parameterizations in warm rain formation of cumulus clouds}

J. Sun et al.

Title Page

Abstract

Conclusions

Tables

14

Back

\section{Introduction}

References

Figures

$>1$

Close

\section{Full Screen / Esc}

Printer-friendly Version

Interactive Discussion 